\title{
Dynamic regulation and requirement for ribosomal RNA transcription during mammalian development
}

Authors: Karla T. Falcon ${ }^{1} \uparrow$, Kristin E.N. Watt ${ }^{1} \uparrow$, Soma $_{\text {Dash }}{ }^{1} \uparrow$, Annita Achilleos ${ }^{1,3}$, Ruonan Zhao $^{1,2}$, Daisuke Sakai ${ }^{1,4}$, Emma L. Moore ${ }^{1}$, Sharien Fitriasari ${ }^{1}$, Melissa Childers ${ }^{1}$, Mihaela E. Sardiu $^{1,5}$, Selene Swanson ${ }^{1}$, Dai Tsuchiya ${ }^{1}$, Jay Unruh ${ }^{1,}$ George Bugarinovic ${ }^{1,6}$, Lin Li ${ }^{7}$, Rita Shiang $^{7}$, Jill Dixon ${ }^{8}$, Michael J. Dixon ${ }^{8}$, Paul A. Trainor ${ }^{1,2}$

\author{
Affiliations: \\ ${ }^{1}$ Stowers Institute for Medical Research, Kansas City, MO, USA \\ ${ }^{2}$ Department of Anatomy and Cell Biology, University of Kansas Medical Center, Kansas City, \\ KS, USA \\ ${ }^{3}$ Baylor College of Medicine, Houston, TX, USA \\ ${ }^{4}$ Department of Biology, Kanazawa Medical University Uchinada, Kahoku, Ishikawa, Japan \\ ${ }^{5}$ Department of Biostatistics \& Data Science, University of Kansas Medical Center, Kansas \\ City, KS, USA \\ ${ }^{6}$ Department of Orthopedic Surgery, Stanford University, Redwood City, CA, USA \\ ${ }^{7}$ Department of Human and Molecular Genetics, Virginia Commonwealth University, \\ Richmond, VA, USA \\ ${ }^{8}$ Faculty of Biology, Medicine and Health, University of Manchester, Manchester, United \\ Kingdom \\ $\dagger$ Equal contribution. \\ *Correspondence to: Paul A. Trainor, pat@stowers.org
}




\section{Significance statement:}

RNA Polymerase I (Pol I) mediated rRNA transcription is required for protein synthesis in all tissues for normal growth and survival as well as for proper embryonic development. Interestingly, disruptions in Pol I mediated transcription perturb ribosome biogenesis and lead to tissue-specific birth defects, which commonly affect the head and face. Our novel results show that during mouse development, Pol I mediated rRNA transcription and protein translation is tissue-specifically elevated in neural crest progenitors and neural crest cells, which give rise to bone, cartilage, and ganglia of the head and face. Using new mouse models, we further show that neural crest cells are highly sensitive to disruptions in Pol I and that when rRNA synthesis is genetically downregulated, it specifically results in craniofacial anomalies. 


\begin{abstract}
:
Ribosomal RNA (rRNA) transcription by RNA Polymerase I (Pol I) is a critical ratelimiting step in ribosome biogenesis, which is essential for cell survival. Despite its global function, disruptions in ribosome biogenesis cause tissue-specific birth defects called ribosomopathies which frequently affect craniofacial development. Here, we present a cellular and molecular mechanism to explain the susceptibility of craniofacial development to disruptions in Pol I transcription. We show that Pol I subunits are highly expressed in the neuroepithelium and neural crest cells (NCC), which generate most of the craniofacial skeleton. High expression of Pol I subunits sustains elevated rRNA transcription in NCC progenitors, which supports their high tissue-specific levels of protein translation, but also makes NCC particulalry sensitive to rRNA synthesis defects. Underpinning these findings, NCC-specific deletion of Pol I subunits Polrla, Polrlc, and associated factor Tcofl in mice cell-autonomously diminishes rRNA synthesis, which causes an imbalance between rRNA and ribosomal proteins. This leads to increased ribosomal protein binding to $\mathrm{Mdm} 2$ and concomitantly diminished $\mathrm{Mdm} 2$ binding to p53. Consequently, p53 protein accumulates, resulting in NCC apoptosis and craniofacial anomalies. Furthermore, compound mutations in Pol I subunits and associated factors specifically exacerbates the craniofacial anomalies characteristic of the ribosomopathies Treacher Collins Syndrome and Acrofacial Dysostosis Cincinnati Type. Our novel results therefore demonstrate the dynamic spatiotemporal requirement for rRNA transcription during mammalian cranial NCC development and corresponding tissue-specific threshold sensitivities to disruptions in rRNA transcription in the pathogenesis of craniofacial congenital diseases.
\end{abstract}




\section{Main Text:}

Ribosomal RNA (rRNA) transcription and ribosome biogenesis are critical for cell growth, proliferation, differentiation, and survival. Ribosomes translate cellular proteins and are responsible for the quality and quantity of proteins ${ }^{1,2}$. The ability to modulate translation rates and translation capacity to meet cell-specific needs is regulated in part by the number of ribosomes available to translate mRNAs ${ }^{2-5}$. The synthesis of ribosomes is primarily determined by RNA Polymerase (Pol) I-mediated rRNA transcription, which is a critical rate-limiting step in ribosome biogenesis ${ }^{6,7}$. Pol I is a 13 subunit complex ${ }^{8}$ that transcribes the $47 \mathrm{~S}$ precursor rRNA, which is then modified, processed, and cleaved into $5.8 \mathrm{~S}, 18 \mathrm{~S}$, and $28 \mathrm{~S}$ rRNAs. To assemble the mature ribosome, these rRNAs associate with Pol III transcribed 5S rRNA and small nucleolar RNAs, and ribosomal and accessory proteins transcribed by Pol II. rRNA forms the catalytic core of the ribosome that joins amino acids to form peptides ${ }^{9}$. rRNA transcription is a key regulator of ribosome quantity and translation, and accounts for about $60 \%$ of all cellular transcription $^{2,10}$. Furthermore, rRNA synthesis is integral to increased protein translation during cell growth, proliferation, and other metabolic needs.

Considering the requirement for Pol I mediated rRNA transcription and ribosome biogenesis in all cell types, it is surprising that defects in these processes result in tissue-specific developmental disorders or cancers known as ribosomopathies ${ }^{11-14}$. For example, mutations in the Pol I catalytic subunit POLR1A result in Acrofacial Dysostosis Cincinnati Type (AFDCIN) $)^{15}$ whereas mutations in POLRIC and POLRID ${ }^{16}$, shared subunits of Pol I and III ${ }^{17}$, or Pol I associated factor TCOF1 cause Treacher Collins Syndrome (TCS) ${ }^{18,19}$. TCOF1 encodes the nucleolar phosphoprotein TREACLE, which is involved in rRNA transcription and processing ${ }^{20,21}$. AFDCIN and TCS present with a range of phenotypes that primarily affect craniofacial skeletal development including micrognathia, cleft palate, and malar 
hypoplasia $^{15,18,19}$. However, despite previous work which has elucidated the basic functions of the proteins involved in rRNA transcription and ribosome biogenesis in various organisms including yeast and human cell lines ${ }^{22-24}$, the mechanisms by which disruptions in Pol I-mediated transcription result in tissue-specific phenotypes remain poorly understood. In particular, if rRNA transcription is tissue-specifically required during mammalian craniofacial development and why cranioskeletal development is highly susceptible to defects in rRNA transcription are yet to be determined.

We hypothesized that different cells and tissues have distinct threshold requirements for rRNA transcription, ribosome biogenesis, and protein synthesis to meet their cell-specific needs, and that this leads to distinct cell and tissue-specific threshold sensitivities to deficiencies in rRNA transcription. NCC are a transient progenitor population derived from the neuroepithelium via an epithelial-to-mesenchymal transition (EMT), which then delaminate, proliferate, and migrate into the frontonasal prominences and pharyngeal arches (PAs) where they differentiate into most of the craniofacial bone and cartilage, among other tissues. Given the high incidence of cranioskeletal defects in ribosomopathies, we hypothesized that neural crest cells (NCC) are one of the cell types that require high levels of rRNA and protein synthesis. We therefore examined the role of Pol I in NCC during craniofacial development. Through lineage tracing, expression, and translation analyses, we discovered that neuroepithelial cells and NCC exhibit elevated levels of rRNA transcription which correlate with high levels of protein translation compared to surrounding cells during early embryogenesis. To understand the intrinsic function of Pol I mediated transcription in NCC, we generated mammalian models of Pol I disruption via null and conditional tissue-specific deletion of a catalytic subunit (Polrla), non-catalytic subunits (Polrlc, Polrld), and associated factor (Tcof1) of Pol I in mice. We discovered that these factors 
synergistically interact, that Pol I mediated transcription is essential for cell survival, and that cranial NCC are particularly sensitive to decreased rRNA transcription during early craniofacial development. Pol I subunit and associated factor loss-of-function results in rRNA deficiency, which perturbs the stoichiometric balance between rRNA and ribosomal proteins, leading to ribosomal proteins RPL5 (uL18) and RPL11 (uL5) binding to Mdm2. This diminishes Mdm2's ability to bind to and target p53 for degradation. Consequently, p53 accumulates in the nucleus causing NCC apoptosis and craniofacial anomalies. Thus, developmental ribosomopathy phenotypes are caused by the tissue-specific post-translational accumulation of p53 protein in response to perturbation of tissue-specific rRNA and ribosome biogenesis needs. Taken together, our novel work demonstrates the dynamic tissue-specific regulation and requirement for rRNA transcription during craniofacial development that mechanistically accounts for tissue-specific threshold sensitivities to perturbation of rRNA transcription. Finally, our data shows that ubiquitously expressed genes thought to play fundamental housekeeping functions, exhibit cell type specific functions and provides novel insights into the roles of rRNA transcription in regulating embryonic development and disease.

\section{Results}

\section{Cranial NCC have high levels of rRNA and protein synthesis}

Mutations in Pol I subunits result in tissue-specific craniofacial anomalies in humans ${ }^{16,25}$. We hypothesized that the underlying cause for these tissue-specific defects is due to differential transcription of rRNA in NCC during early embryogenesis. We therefore performed ViewRNA® in situ hybridization ${ }^{26}$ for the $47 \mathrm{~S}$ pre-rRNA 5'ETS (Fig. 1A), as a measure of nascent transcription $^{27,28}$ in Wnt1-Cre; ROSAeYFP mouse embryos, which lineage labels the dorsal 
neuroepithelium, including NCC progenitors and their descendants with $\mathrm{YFP}^{29}$. At embryonic day (E) 8.5, during NCC formation and early migration, 5'ETS expression was significantly higher in NCC (YFP+ cells) versus surrounding non-NCC (Fig. 1 B, b, D). At E9.5, during later migration and onset of differentiation, 5'ETS expression remained higher in NCC versus nonNCC (Fig. 1 C, c, D), although the difference was less than observed at E8.5. This indicates that NCC have endogenously high levels of rRNA transcription at early stages of development while they are in a more progenitor and highly proliferative state compared to surrounding tissues.

Given its importance as a rate-limiting step in ribosome biogenesis and the production of ribosomes that translate all cellular protein, we hypothesized that high rRNA transcription in NCC would correlate with elevated protein synthesis. To test this idea, we performed Click-iT OPP® (O-propargyl-puromycin) labeling ${ }^{30}$ as a measure of translation in Wnt1-Cre; ROSAeYFP embryos, which revealed that cranial NCC do indeed exhibit significantly higher protein synthesis compared to other surrounding cells at E8.5, and slightly higher (although not statistically significant) levels of protein synthesis at E9.5 (Fig. 1 E-G). To determine whether increased rDNA transcription and translation correlates with tissue-specific proliferative capacity, we performed 5-bromo-2'-deoxyuridine (BrdU) incorporation in E8.5 wild-type embryos and immunostained transverse sections for BrdU and the mitotic marker phosphoHistone $\mathrm{H} 3$ (pHH3). We observed that the neuroepithelium, which includes pre-migratory NCC, is more proliferative than the surrounding mesoderm and endoderm (Fig. S1 A, B). Together, these observations reveal a correlation between high proliferation with elevated rRNA transcription and protein synthesis at E8.5 in neuroepithelial cells and progenitor NCC. Consequently, we posited that the neuroepithelium and NCC would be particularly sensitive to disruptions in Pol I-mediated rRNA transcription during embryonic development. Culturing E8.5 
wild-type mouse embryos for as short as 8 hours with a Pol I inhibitor BMH-21 ${ }^{31}$, resulted in apoptosis specifically in neuroepithelial cells and NCC progenitors (Fig. $1 \mathrm{H}-\mathrm{I}, \mathrm{h}-\mathrm{i}$ ). Our data therefore demonstrates that endogenously high rRNA transcription and protein translation in the neuroepithelium and progenitor NCC underpins their cell survival-specific threshold sensitivity to disruptions in Pol I.

\section{Polr1a, Polr1c, Polr1d, and Tcof1 are broadly expressed with elevated levels in the} neuroepithelium and pharyngeal arches

To understand if tissue-specific differences in rRNA transcription correlate with differential expression of Pol I subunits during embryogenesis, we examined the expression of Polr1a, Polr1c, Polr1d and the associated factor Treacle, which is encoded by Tcofl, during early embryogenesis. Polrla ${ }^{\text {bgeo/+ }}$, Polrl $c^{\text {bgeo/+ }}$, and Polrld ${ }^{\text {bgeo/+ }}$ mice carrying a gene trap vector with a $\beta$ Geo cassette in the endogenous locus of each gene were generated (Fig. S2 A), allowing for evaluation of Polr1a, Polr1c, and Polr1d spatiotemporal expression by LacZ staining. Polr1a, Polr1c, and Polr1d are broadly expressed at E8.5 and E9.5 (Fig. 2 A-C, I-K) with high levels of expression in the neuroepithelium, and PA, which are the bilateral structures that develop into the jaw and neck (Fig. 2 E-G, M-O). Similarly, Treacle immunostaining of wild-type embryos revealed broad expression in E8.5 and E9.5 embryos, with elevated levels in the neuroepithelium and PA (Fig. 2 D,H,L,P). Furthermore, single-cell RNA sequencing of E8.5 embryos revealed that all of the Pol I subunits, including Polrla, Polrlc, and Polrld, as well as Tcofl are expressed broadly in progenitor craniofacial cells and tissues (Fig. S2), but each exhibits enriched expression in the neuroepithelium and NCC. Altogether, this suggests that elevated 
expression of Pol I subunits and associated factor Tcofl in the neuroepithelium and NCC contribute to their high levels of rRNA transcription.

To determine the function of individual Pol I subunits during development, heterozygous and homozygous Polrla, Polrlc, and Polrld mutant mice were generated (Fig. S3). Polr1a ${ }^{+/}$, Polrlc ${ }^{+/}$, and Polrld ${ }^{+/-}$embryos are morphologically indistinguishable from their wild-type littermates at E18.5 and survive to adulthood, indicating that a single copy of each gene is sufficient for proper development in mice (Fig. S3 B). However, Polrla ${ }^{-/}$, Polrl $c^{-/}$, and Polrld $d^{-/}$ embryos are embryonic lethal by E3.5 (Fig. S3 C). Their failure to develop into blastocysts demonstrates that these genes are necessary for survival during pre-implantation mammalian development.

\section{Polr1a, Polr1c, and Polr1d genetically and physically interact with Tcof1 during craniofacial development}

Given their largely overlapping expression patterns with elevated levels in the neuroepithelium and NCC, together with their shared Pol I associated function in rRNA transcription, we hypothesized that Polrla, Polrlc, and Polrld synergistically interact with Tcofl during mouse craniofacial development. In support of this idea, we performed MultiDimensional Protein Identification Technology (MudPIT) ${ }^{32,33}$ analysis of HEK293T-derived cell lines stably expressing FLAG-tagged TREACLE and found that TREACLE binds to specific Pol I subunits, including POLR1A and POLR1C, together with previously known targets such as Casein kinase 2 (CSNK2) (Fig. 3A, Fig. S4, Table S1) ${ }^{34}$. Thus, POLR1A, POLR1C, and TREACLE interact at a protein level consistent with being components and associated factors of Pol I. 
To test whether these factors also interact at a genetic level we generated $T$ cof $1^{+/}$; Polrla ${ }^{+/}$, Tcof1 $^{+/-} ;$Polrlc ${ }^{+/-}$, and Tcof1 $^{+/-} ;$Polrld $d^{+/-}$double heterozygous mutants. As previously described ${ }^{35,36}$, E18.5, Tcof $^{+/-}$mouse embryos display craniofacial malformations including domed-shaped heads, hypoplasia of the skull, nasal, premaxillary and maxillary bones, together with partially penetrant cleft palate, ear and eye abnormalities (Fig. 3 B, D, I), which phenocopies TCS in humans. By comparison, each of the E18.5 double heterozygote mutants exhibit considerably more severe craniofacial defects than found in $T c o f 1^{+/}$embryos (Fig. 3 B, D-G). Double heterozygotes display exacerbated craniofacial malformations including fully penetrant cleft palate together with exencephaly and microphthalmia (Fig. 3 B-L). Furthermore, alcian blue and alizarin red staining revealed the comparatively more severe hypoplasia and malformation of craniofacial cartilage and bone, particularly of the skull, maxilla and mandible (Fig. 3 I-L), illustrating the particular sensitivity of craniofacial tissues to perturbations in Pol I function.

Interestingly, the double heterozygous mutant embryos also exhibit variably penetrant developmental anomalies outside of the craniofacial region, which were not observed in $T$ cof $1^{+/}$ embryos. This includes thoracoschisis or omphalocele (fissure of the thoracic or abdominal wall) (Fig. 3B; Fig. S5 A-E), as well as limb and digit anomalies, such as long bone hypoplasia, and abnormal number or short and broad digits (Fig. S5 F-J). The exacerbated and complete penetrance of cranioskeletal malformations compared to partial penetrance of other tissue anomalies demonstrates the different threshold sensitivities of distinct tissues to global disruptions in Pol I function. These protein and genetic interactions and the synergistic effects of their loss-of-function reiterate the importance of tissue specific levels of rRNA transcription and 
suggest that Polrla, Polrlc, Polrld, and Tcofl function together in rRNA transcription in mammalian NCC during craniofacial development.

\section{NCC-specific deletion of Polr1a, Polr1c, and Tcof1 results in craniofacial defects}

Elevated rRNA transcription in NCC progenitors and NCC and the high sensitivity of neuroepithelial and craniofacial tissues to defects in rRNA transcription implies a cell autonomous role for Polrla, Polrlc, and Tcofl in Pol I transcription in NCC during early development. We therefore conditionally deleted these factors in NCC during their formation. Wnt1-Cre recombinase is expressed in the dorsal neuroepithelium, which includes NCC progenitors beginning at E8.5 ${ }^{29,37}$. We crossed Wnt1-Cre mice with Polrla ${ }^{f l x f f l x}$, Polrlc $c^{f l x / f l x}$, or Tcofl ${ }^{f l x f l x}$ mice to generate NCC-specific knockouts (NKO) of Polrla, Polrlc, and Tcofl (Fig. S6 A). The levels of Polrla, Polrlc, and Tcofl transcripts in NCC were reduced in E9.5 Polrla ${ }^{N K O / N K O}$, Polrl $c^{N K O / N K O}$, and Tcof1 $1^{N K O / N K O}$ mutant embryos, respectively, relative to littermate Polr $1 a^{N K O /+}, P o l r l c^{N K O /+}$, and $T \operatorname{cof} 1^{\mathrm{NKO} /+}$ controls confirming Cre-mediated excision of exons flanked by loxP sites (Fig. S6 B).

E9.5 Polrla ${ }^{N K O / N K O}$, Polr $1 c^{N K O / N K O}$, and Tcof1 ${ }^{N K O / N K O}$ mutants present with visibly hypoplastic frontonasal prominences and PAs when compared to littermate controls, a phenotype that worsens considerably by E10.5-E11.5 (Fig. 4 A-D; Fig. S7 A-H). To determine whether this tissue hypoplasia was a consequence of perturbed NCC development, we crossed ROSAeYFP into the background of Polrla $a^{N K O / N K O}, P o l r 1 c^{N K O / N K O}$, and $T c o f 1^{N K O / N K O}$ mice to indelibly label the NCC lineage with YFP. This revealed that NCC migrate into the facial prominences and PAs in $N K O$ mutants by E9.5. However, the smaller facial outgrowths in these mutants appear to correlate with reduced populations of NCC (Fig. S7 I-L), a phenotype which is even more 
pronounced at E10.5 in the $N K O$ mutants compared to littermate controls (Fig. 4 E-H; Q-T). Polrla ${ }^{\text {NKO/NKO }}$ embryos die around E11.5, whereas Polrlc ${ }^{N K O / N K O}$ and Tcof1 $1^{\text {NKO/NKO }}$ embryos survive until E12.5 and E13.5 respectively (Fig. S6C), conveying the relative importance of Polrla, Polrlc, and Tcofl in NCC for embryo survival.

NCC differentiate into a wide variety of cell and tissue derivatives including neurons in the peripheral nervous system and osteochondroprogenitors of craniofacial cartilage and bone. Neuron-specific class III $\beta$-tubulin (TuJ1) immunostaining revealed that E10.5 NKO mutants exhibit hypoplastic cranial ganglia, together with diminished nerve projections compared to littermate controls (Fig. 4 I-L). The early lethality of $N K O$ mutant embryos prevented analysis of NCC differentiation into mature cartilage and bone. Therefore, we investigated the specification of NCC into osteochondroprogenitors. The expression of Sox9, a master regulator of chondrogenesis, and its downstream target, $\mathrm{Col}_{2} a \mathrm{I}^{38}$, were both diminished in the facial prominences in E9.5 and E10.5 NKO mutants compared to controls (Fig. 4 M-P, Fig. S7 M-T, mp). The reduced domains of chondrogenic gene expression together with hypoplasia of the cranial ganglia, correlate with a diminished NCC population and smaller craniofacial prominences and PAs (Fig. 4 Q-T), suggesting that Polrla, Polrlc, and Tcofl play critical roles in NCC proliferation and/or survival.

\section{Polr1a, Polr1c, and Tcof1 loss-of-function in NCC leads to reduced proliferation and increased NCC death}

We hypothesized that decreased proliferation and/or increased apoptosis accounts for the reduced NCC population in NKO mutants. Transverse sections of E9.5 Polr1a ${ }^{\text {NKO/NKO; }}$

ROSAeYFP, Polrlc $c^{N K O / N K O} ;$ ROSAeYFP, and Tcof1 ${ }^{\text {NKO/NKO }}$; ROSAeYFP embryos stained for the 
mitotic proliferation marker $\mathrm{pHH} 3$ displayed fewer $\mathrm{pHH} 3+\mathrm{NCC}$ compared to littermate controls

(Fig. 5 A-D, a-d; Fig. S8 A). Conversely, TUNEL staining of Polrla $a^{N K O / N K O} ;$ ROSAeYFP, Polrl $c^{N K O / N K O} ;$ ROSAeYFP, and Tcof1 $1^{N K O / N K O} ;$ ROSAeYFP mutant embryos revealed significantly increased NCC apoptosis (Fig. 5 E-H, e-h; Fig. S8 B). p53 is a well-known mediator of apoptosis ${ }^{39}$ and we therefore tested for $p 53$ expression but observed no changes in p53 transcription in the NCC of Polrla ${ }^{N K O / N K O}$ mutants compared to Polrla ${ }^{N K O /+}$ controls (Fig. S9). Interestingly, p53 protein is uniformly expressed at very low levels in wild-type E8.5 embryos $^{40}$, and although $p 53$ was not affected at the transcript level, p53 protein was tissuespecifically increased in the NCC in NKO mutants compared to their respective littermate controls (Fig. 5 I-L; Fig. S8 C). Furthermore, we observed a significant increase in $p 21$ in $N K O$ mutants compared to controls (Fig. S9), indicative of the activation of downstream targets of p53 in NCC. Hence, the NCC population in $N K O$ mutants is diminished primarily due to a cell autonomous tissue-specific increase in p53 protein-dependent cell death (Fig. $5 \mathrm{M}$ ).

\section{Excision of Polr1a, Polr1c, and Tcof1 results in decreased rRNA and protein synthesis}

Pol I subunits and associated factor Treacle play central roles in rRNA transcription, which when disrupted, can result in $\mathrm{p} 53$-dependent apoptosis ${ }^{15,17,40}$. To determine if disruptions in rRNA transcription underlie the increased p53-dependent cell death observed in $N K O$ mutants, we analyzed rRNA transcription in fluorescence activated cell (FAC) sorted NCC by quantitative RT-PCR (qPCR). The 5'ETS was significantly downregulated in Polrla ${ }^{N K O / N K O} ;$ ROSAeYFP and Tcof1 ${ }^{\text {NKO/NKO }}$; ROSAeYFP NCC when compared to respective control NCC (Fig. 6A). While

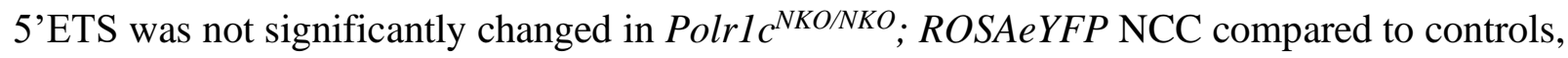
$28 \mathrm{~S}$ rRNA, which reflects the level of the precursor 47S transcript and the mature $28 \mathrm{~S}$ rRNA, 
was significantly reduced (Fig. 6A). Overall, our data demonstrates that rRNA transcription is reduced in Polrla, Polrlc and Tcofl NKO mutants.

rRNA transcription is a rate limiting step in ribosome biogenesis, and we therefore hypothesized that protein synthesis would consequently be reduced in Polrla, Polr1c, and Tcofl NKO NCC. Protein was extracted from FAC sorted NCC (YFP+) and non-NCC (YFP-) cells from Polrla ${ }^{N K O / N K O} ;$ ROSAeYFP, Polrl NKO/NKO $^{\text {NOSAeYFP, and Tcofl }}{ }^{\text {NKO/NKO }}$; ROSAeYFP mutant embryos and their respective controls, and silver staining ${ }^{41}$ revealed a significant decrease in total protein in Polrla, Polrlc, and Tcofl NKO NCC relative to control NCC (Fig. 6B, Fig. S10). This demonstrates that Polrla, Polrlc, and Tcofl loss-of-function in NCC leads to a cell-autonomous reduction in rRNA transcription and total protein, which results in increased p53-dependent NCC apoptosis and consequently craniofacial anomalies.

\section{Polr1a, Polr1c and Tcof1 deletion results in Rpl5 and Rpl11 binding to Mdm2 and p53 stabilization}

To investigate how Pol I disruption activates p53-dependent apoptosis, we generated mouse embryonic fibroblasts (MEFs) from Polrla $a^{f l x f f l x}$, Polrl $c^{f l x f f l x}$, and Tcof $1^{f l x f f l x}$ mice crossed to tamoxifen inducible $\mathrm{Cre}-E R^{T 2}$, hereafter referred to as tamoxifen-inducible knockouts $(t K O)$. As expected, Polrla, Polrlc, and Tcofl transcripts were decreased in Polrla ${ }^{t K O / t K O}$, Polr $1 c^{t K O / t K O}$, and Tcof $1^{t K O / t K O}$ MEFs compared to Polrla $a^{f l x f f l x}$, Polr $1 c^{f l x / f l x}$, and Tcof $f^{f l x f l x}$ control MEFs, 48 hours after tamoxifen induced Cre activation (Fig. S11 A-C). Consequently, protein synthesis was decreased in the mutant MEFs (Fig. S11 D-F) while conversely, the levels of p53 were increased (Fig. S12), demonstrating the mechanistic equivalency between $t K O$ MEFs and $N K O$ embryos. 
During normal cell growth and proliferation, p53 typically exhibits a short half-life, due in large part to HDM2 (Human Double Minute 2, also known as Mdm2), which binds to and ubiquitinates p53, targeting it for degradation ${ }^{42}$. Mdm2 prevents the accumulation of excess p53 even under conditions of cell stress. However, it has been proposed from in vitro studies that when there is an imbalance in the normal stoichiometric ratio of rRNA and ribosomal proteins, free or excess ribosomal proteins, particularly Rpl5 (uL18) and Rpl11 (uL5), bind to Mdm2, inhibiting its function $22,23,43-45$. rRNA transcription is decreased in Polrla, Polr1c, and Tcof1 NKO embryos; however, western blots showed that the levels of Mdm2, and ribosomal proteins Rpl5 and Rpl11, remain unchanged in $t K O$ MEFs compared to controls (Fig. S12). Interestingly, immunoprecipitation followed by immunoblotting revealed increased binding of Rp15 and Rpl11 to $\mathrm{Mdm} 2$, in concert with decreased binding between Mdm2 and p53 in $t K O \mathrm{MEF}$ compared to controls (Fig. 7). These results suggest that disruptions in Pol I-mediated rRNA transcription alter the stoichiometric balance between rRNA and ribosomal proteins, resulting in increased Rpl5 and Rpl11 binding to Mdm2. This diminishes Mdm2 from binding and ubiquitinating p53, leading to tissue-specific p53 accumulation, which can account for the tissue-specific neuroepithelial cell and NCC apoptosis, reduction in NCC, and craniofacial anomalies characteristic of many ribosomopathies (Fig. S13).

\section{Discussion}

rRNA transcription is essential for normal embryo development and our novel mouse knockouts of Polrla, Polrlc, Polrld and Tcofl demonstrate that Pol I function is critical for post-implantation survival. But why craniofacial development is highly sensitive to perturbations 
in global rRNA transcription and Pol I function in humans and animal models ${ }^{15,17,18,35}$ remains a critical gap in our knowledge.

Our data demonstrates that rRNA synthesis is tissue-specifically regulated in-vivo during mouse embryogenesis and that this correlates with tissue-specific threshold sensitivities to disruptions in rRNA transcription. First, quantification of the 5'ETS of 47S pre-rRNA showed that the neuroepithelium and NCC exhibit endogenously high levels of rRNA transcription compared to surrounding non-NCC (Fig. 1). Second, single cell RNA-sequencing, LacZ staining, and immunostaining revealed that the high levels of rRNA could be mechanistically underpinned by dynamically enriched expression of Tcofl, Polrla, Polr1c, Polrld, and other Pol I subunit transcripts and protein in the neuroepithelium and NCC in mice (Fig. 2 and S2). This correlates with elevated translation in the neuroepithelium and NCC progenitors, which is necessary to meet high proliferation needs and possibly other demands such as the requirement to translate new proteins for cytoskeletal rearrangement during $\mathrm{EMT}^{46}$ (Fig. 1; Fig. S1; Fig. S13). Third, global Pol I inhibition with BMH-21 results in apoptosis specifically in neuroepithelial cells and NCC progenitors in E8.5 mouse embryos (Fig. 1). Therefore, taken together with our previous observations in zebrafish ${ }^{15,17}$, this indicates that NCC progenitors have high rRNA transcription and are highly sensitive to disruptions in rRNA synthesis.

Further demonstrating the tissue-specific threshold sensitivities to disrupted rRNA transcription, craniofacial anomalies are more severe and $100 \%$ penetrant in Tcof1 $^{+/-}$; Polrla ${ }^{+/-}$, Tcof1 $1^{+/} ;$Polrlc $c^{+/-}$, and Tcof1 ${ }^{+/} ;$Polrld $d^{+/}$double heterozygous mutants compared to craniofacial anomalies observed in $\mathrm{Tcofl}^{+/-}$mutant embryos, indicating cranial NCC-specific responses to disruptions in rRNA transcription (Fig. 3). We also observed malformations in noncraniofacial tissues in double heterozygous mutants which are not present in $\mathrm{Tcofl}^{+/}$embryos, 
indicating non-NCC derived tissues are also affected, although to a lesser degree. This demonstrates that distinct tissue-specific threshold sensitivities to disruptions in rRNA transcription influence the severity of developmental anomalies, which is reflected in the phenotypes of ribosomopathies in humans such as TCS and AFDCIN.

Finally, Pol I mediated transcription functions in a cell autonomous manner during mouse NCC development. NCC-specific deletion of Polrla, Polrlc and Tcofl genes results in NCC autonomous reductions in rRNA transcription and consequently, craniofacial anomalies (Fig. 4, 6). Likely due to an ensuing imbalance between rRNA and ribosomal proteins ${ }^{22}$, we observed increased binding between Rpl5 and Rpl11 with Mdm2 and a concomitant reduction in Mdm2 binding to p53 (Fig. 7). The diminished ability of Mdm2 to target p53 for degradation correlates with the post-translational accumulation of p53 and subsequent NCC apoptosis (Fig. 5, Fig. S13). These findings mechanistically account for the reduced chondroprogenitors and hypoplasia of craniofacial bone and cartilage observed in the $N K O$ embryos (Fig. 4), which are more severe in Polrla $a^{N K O / N K O}$ embryos compared to Polrl $c^{N K O / N K O}$ and Tcofl $1^{N K O / N K O}$ embryos. This is consistent with Polr1a forming part of the catalytic site of Pol I, whereas Polr1c functions to hold Polr1a and Polr1b together but does not form part of the catalytic site, while Treacle, is an associated factor that interacts with Pol ${ }^{47}$. Thus, altogether, our data shows that the neuroepithelium and NCC are particularly sensitive to deficiencies in rRNA in association with their survival needs.

How disruptions in rRNA transcription and ribosome biogenesis result in cell typespecific apoptosis is still not fully understood. While p53 signaling has been implicated in multiple ribosomopathies ${ }^{39}$, the molecular mechanism underlying elevated p53 in different pathologies remains unclear. Contrary to previous literature that implicates higher transcription 
of $p 53$ in the NCC compared to surrounding cells as a potential reason for neurocristopathies ${ }^{48}$, we observe that p53 transcript quantity is similar in NCC and other craniofacial cell types during early embryogenesis. Furthermore, previous data shows that p53 protein levels are uniformly low in the neuroepithelium and surrounding tissues in wildtype embryos ${ }^{40}$. However, in the absence of Pol I subunits or Tcof1, p53 protein is tissue-specifically upregulated in a cell autonomous manner (Fig. 5; Fig. S8; Fig. S9). We demonstrate that post-translational p53 activation in Polrla, Polr1c and Tcofl loss-of-function mutants results from an imbalance between rRNA transcription and ribosomal proteins, such that excess Rpl5 and Rpl11 bind to Mdm2, limiting its ability to bind to and ubiquitinate $\mathrm{p} 53$. This leads to $\mathrm{p} 53$ protein accumulation and ultimately NCC cell death. Collectively our data suggests that it is not p53 RNA transcription, but cell and tissue specific sensitivity to perturbations in rRNA transcription that result in cell autonomous tissue-specific post-translational activation of $\mathrm{p} 53$ protein in NCC which underpins the pathogenesis of craniofacial anomalies characteristic of TCS and AFDCIN. This mechanism may also account for other ribosomopathies in which deficiencies in specific ribosomal proteins or increased rRNA transcription ${ }^{49}$ are associated with p53-dependent cell death ${ }^{50,51}$ and emphasizes the importance of balanced rRNA and ribosomal protein production in these pathologies.

Our data suggests that the tissue-specific regulation of rRNA has important implications across multiple diseases and tissue types. Signaling pathways such as mTORC1 ${ }^{52}$, MAP kinase $(\mathrm{ERK})^{53}, \mathrm{c}-\mathrm{Myc}^{54}$, and $\mathrm{AKT}^{54,55}$ have been associated with the regulation of global rRNA transcription and proliferation in cancer, while tissue-specific expression and function of ribosomal proteins and pre-ribosomal factors contribute to the pathogenesis of several developmental ribosomopathies ${ }^{56,57}$. However, the dynamic cell and tissue-specific regulation of rRNA expression during development is not well understood. Recent studies have observed 
tissue-specific expression of rRNA in the mouse eye and ovary ${ }^{27,28}$, during forebrain development $^{58}$, and during EMT transitions ${ }^{46,56}$. The level of rRNA in these tissues was hypothesized to correlate with levels of proliferation, similar to our data for the neuroepithelium and NCC (Fig. 1, S1) in E8.5 embryos and our previous observations of neuroepithelial cell apoptosis and decreased proliferation in association with decreased rRNA transcription in E8.5 Tcofl $^{+/-}$mouse embryos ${ }^{35,40}$. Interestingly, the differential levels of rRNA transcription in NCC compared to surrounding cells begins to decrease by E9.5, suggesting that NCC progenitors are more sensitive than NCC at a later developmental stage as they transition from formation, proliferation and migration to differentiation. Consistent with this idea, reductions in rRNA transcription have previously been observed in association with differentiation in other systems $^{58-60}$.

Other factors may also contribute to dynamic tissue-specific rRNA transcription beyond a proliferation and survival versus differentiation demand. This includes epigenetic changes in rDNA $^{61}$, rDNA copy number variation ${ }^{62}$, tissue-specific expression of variant rRNA alleles ${ }^{61}$, or regulation of rRNA synthesis by transcription factors such as Snail1 ${ }^{46}$ and Runx $2^{63}$ which are involved in epithelial-to-mesenchymal transition or osteochondroprogenitor differentiation, respectively. Hence, many pathways potentially regulate rRNA transcription in different tissues and at varying developmental time points to control cell growth, proliferation, survival, and differentiation to meet cell and tissue specific developmental needs. Our data suggests that endogenous differential Pol I subunit and Tcofl gene expression contributes to the dynamic tissue-specific regulation of rRNA. However, further work is needed to determine the upstream mechanisms that modulate the expression of Pol I and Pol I-mediated transcription, especially in the context of development and disease. 
In summary, our novel work uncovered the dynamic tissue-specific regulation and requirement for rRNA transcription during mammalian embryonic development, which mechanistically accounts for the corresponding tissue-specific threshold sensitivities to disruptions in rRNA transcription, particularly in NCC during craniofacial development. Lossof-function of Pol I catalytic subunit (Polr1a), non-catalytic subunit (Polr1c), and associated factor (Tcof1) result in similar phenotypes illustrating the conserved mechanisms underpinning the etiology and pathogenesis of Pol I-related craniofacial birth defects in ribosomopathies such as TCS and AFDCIN. Furthermore, we found that the rRNA-Rpl5/Rp111-Mdm2-p53 molecular pathway which has been previously studied in the context of cancer in yeast and cell lines ${ }^{23,44}$, accounts for the post-translational induction of p53 protein in response to perturbed rRNA transcription and explains why p53 inhibition is able to suppress apoptosis and rescue craniofacial anomalies in mouse $\mathrm{e}^{40}$ and zebrafish ${ }^{17,64}$ models of rRNA transcription deficiency. This raises the possibility that re-establishing the stochiometric ratio between rRNAs and ribosomal proteins could provide a broadly applicable avenue for the therapeutic prevention of ribosomopathies.

\section{Materials and Methods}

\section{Mice and animal husbandry}

Polrla ${ }^{\beta g e o /+}$ and Polrla $a^{f l x f f l x}$

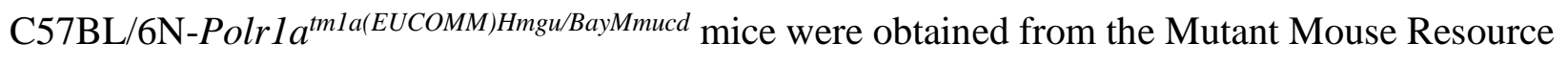

\& Research Center and maintained on a C57BL/6 background. The Polrla ${ }^{\beta g e o /+}$ gene trap knockout ready mice were originally generated at the Baylor College of Medicine by injecting ES cell clone HEPD0779_7_B03 into C57BL/6J-Tyr blastocysts. Resulting male chimeras were 
mated to $\mathrm{C} 57 \mathrm{BL} / 6 \mathrm{~N}$ females, and the progeny were maintained on a C57BL/6N background (56). Polrla ${ }^{\text {tmla }}\left(\right.$ Polrla $\left.a^{\beta g e o /+}\right)$ mice were crossed to FlpO (B6.129S4-

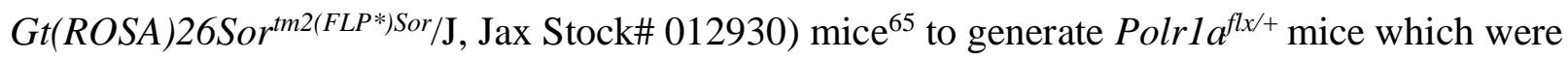
maintained on a C57BL/6 background and then incrossed to generate Polrl $a^{f l x f l x}$ mice (Fig. S2) Polrlc ${ }^{\beta g e o /+}$ and Polrlc $c^{f l x f l x}$

The Polrl $c^{\text {tmla(KOMP)Wtsi }}$ ES cells used to generate the Polrlc ${ }^{\beta g e o /+}$ gene trap knockout ready mouse strain were obtained from the Knock-out mouse project (KOMP) repository. The C57BL/6N parental ES cell line JM8A3.N1 was injected into C57BL/6 blastocysts at the Stowers Institute for Medical Research Laboratory Animal Facility and the Polr1c ${ }^{\beta g e o /+}$ gene trap line was established and maintained on a C57BL/6 background. To generate the Polrl $c^{f l x f f l x}$ line, mice carrying the FLP recombinase (FLPeR) in the Rosa26 locus were crossed to the Polrlc $c^{\beta g e o /+}$ gene trap mice and the resulting Polrl $c^{f l x /+}$ mice were incrossed to homozygosity.

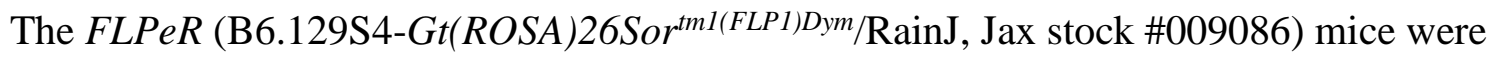
obtained from Jackson Laboratory.

Polrld ${ }^{\text {Bgeo/+ }}$

A C57BL/6 ES cell line (IST10113B8) with a $\beta$ geo gene trap vector inserted into exon 1 of the Polrld gene was obtained from Texas A\&M Institute for Genomic Medicine and injected into C57BL/6 blastocysts at the Stowers Laboratory Animal Facility. Polrld ${ }^{\beta g e o /+}$ mice were maintained on a C57BL/6 background.

$T \operatorname{cof1} 1^{+/-}$and Tcofl $1^{f l x f l x}$

Tcofl $^{+/-}$mice were generated by insertion of neomycin cassette in exon 1 and maintained as previously described ${ }^{66}$ on a DBA background. To generate a conditional allele of Tcofl, exon 1 of Tcofl was flanked by loxP sites using the targeting vector pTKLNCDL (a gift from Dr. 
Richard Mortensen) containing a neomycin cassette and loxP sites. The construct was electroporated into ES cells in 129/SvEv ES (HZ2.2) cells and the ES cells that underwent homozygous recombination were cultured and transiently transfected with $7 \mu \mathrm{g}$ of pCMV-cre by electroporation to remove the neomycin cassette, leaving two loxP sites flanking exon 1 . This recombination in ES cells was confirmed by PCR and Southern blotting and the cells were injected into C57BL/6 blastocysts to generate Tcof $1^{f l x /+}$ mice (Virginia Commonwealth University IACUC \#AM10025). These mice were then backcrossed onto a C57BL/6 background.

Mef2c-F1ON-LacZ

Mef2c-F1ON-LacZ mice in which LacZ is expressed under the control of a neural crest cell specific enhancer of $M e f 2 c$ were maintained as previously described ${ }^{67}$.

\section{Double Mutant Generation}

Tcofl $^{+/-}$mice were crossed to Polrla, Polrlc, or Polrld mice carrying a heterozygous genetrap allele described above.

\section{Neural Crest Cell knockouts and lineage tracing}

Wnt1-Cre mice (H2afv $v^{T g(\text { Wnt1-cre }) 11 R t h} \mathrm{Tg}($ Wnt1-GAL4)11Rth/J, Jax stock \#003829) and RosaeYFP mice were obtained from the Jackson Laboratory and maintained as previously described ${ }^{68,69}$. Polr $1 a^{f l x f f l x}$, Polrl $c^{f l x f f l x}$, and Tcof $1^{f l x / f l x}$ mice were crossed to Wnt1-Cre transgenic mice to generate Polrla ${ }^{f l x /+} ;$ Wnt1-Cre, Polrlc $c^{f l x /+} ;$ Wnt1-Cre, and Tcofl $1^{f l x /+} ;$ Wnt1-Cre mice.

Wnt1-Cre was maintained as a heterozygous allele. To generate Polrla ${ }^{f l x /+} ;$ Wnt1-Cre;RosaeYFP, Polrlc ${ }^{f l x /+} ;$ Wnt1-Cre;RosaeYFP, and Tcof1 ${ }^{f l x /+} ;$ Wnt1-Cre;RosaeYFP mouse lines used for lineage tracing, Polr $1 a^{f l x /+} ;$ Wnt1-Cre, Polr $1 c^{f l x /+} ;$ Wnt1-Cre, and Tcof $1^{f l x /+} ; W n t 1-C r e$ mice were crossed to RosaeYFP (B6.129X1-Gt(ROSA)26Sor tml(EYFP)Cos/J, Jax Stock \#006148) transgenic 
mice. Polrla ${ }^{f l x /+} ;$ Wnt1-Cre, Polrl $c^{f l x /+} ; W n t 1-C r e$, and Tcofl ${ }^{f l x /+} ;$ Wnt1-Cre males were crossed to Polrla $a^{f l x f f l x}$, Polrl $c^{f l x f f l x}$, and Tcofl $1^{f l x f f l x}$ females, respectively to obtain Polrla $a^{f l x f f l x}$;Wntl-Cre, Porll $c^{f l x f f l x} ;$ Wnt1-Cre, and Tcofl $1^{f l x f f l x} ;$ Wnt1-Cre embryos, respectively, which are referred to as Polrla ${ }^{N K O / N K O}$, Polrl $c^{N K O / N K O}$, and Tcofl $1^{N K O / N K O}$ in this paper.

Tamoxifen inducible temporal knockouts

Cre-ER $R^{T 2}\left(\mathrm{~B} 6.129\right.$ - Gt(ROSA)26Sor ${ }^{T M}$ 1(Cre-ERT2)Tyj/J, Jax stock cat\# 008463) mice were crossed to Polrla $a^{f l x f f l x}$, Polr $1 c^{f l x f f l x}$, and Tcoflflxfflx mice to generate Polrla ${ }^{f l x /+} ; C r e-E R^{T 2}, P o l r l c^{f l x /+} ; C r e-$ $E R^{T 2}$, and $T \operatorname{cof} \mathrm{f}^{f l x} /+; C r e-E R^{T 2}$ mice which were subsequently bred to homozygous floxed mice to generate embryos for MEF generation.

The day a vaginal plug was observed in a time mated female was designated as embryonic day (E) 0.5 . All mice were housed in a 16 hour light: 8 hour dark light cycle. All animal experiments were conducted in accordance with Stowers Institute for Medical Research Institutional Animal Care and Use Committee approved protocol (IACUC \#2019-097).

\section{Genotyping}

To confirm recombination, Polrla and Tcofl mice were genotyped according to the primers listed in Supplemental Table 2. Genotyping of all mouse strains was determined using real-time PCR assays with specific Taqman probes designed for each strain (Transnetyx, Inc, Cordova,

$\mathrm{TN}$ )

\section{Brightfield imaging}

Embryos were imaged on a Leica MZ16 microscope equipped with a Nikon DS-Ri1 camera and NIS Elements imaging software. Manual Z stacks were taken and then assembled using Helicon Focus software. Alterations of brightness and contrast were performed in Adobe Photoshop to improve image clarity and applied equally across the entire image. 


\section{MudPIT}

A stable cell line expressing FLAG-tagged TREACLE was generated by transfecting 293-FRT cells with FLAG-Tcof1-pcDNA5/FRT and pOG44 (Invitrogen) using LipofectAMINE $2000^{70}$. Cells were cultured at $37^{\circ} \mathrm{C}$ in a humidified incubator with $5 \% \mathrm{CO}_{2}$. Cells were lysed in lysis buffer (50 mM Tris- $\mathrm{HCl}$ (pH 7.5), $120 \mathrm{mM} \mathrm{NaCl,} \mathrm{0.5 \%} \mathrm{NP-40,} 1 \mathrm{mM}$ EDTA, and proteinase inhibitor cocktail (Nacalai tasque)). Following lysis, $2 \mathrm{mM} \mathrm{MgCl} 2$ and benzonase (50 U/ $\mathrm{ml})$ was added to the whole cell extracts and centrifuged. The supernatant was incubated with agarose beads conjugated with anti-FLAG antibody (Sigma) at $4^{\circ} \mathrm{C}$ overnight. The following day, the beads were precipitated by centrifugation, washed with lysis buffer, and proteins were eluted with the FLAG peptide $(200 \mu \mathrm{g} / \mathrm{ml})$ in lysis buffer and then precipitated by Trichloroacetic acid. MudPIT was performed to identify interacting proteins as described previously ${ }^{32,33}$.

\section{Bone and cartilage staining}

E18.5 embryos were anesthetized by immersion in ice cold PBS for at least 60 minutes until no reflex movements were observed following a pinch test. The skin and viscera were removed, and the embryos were then fixed in $95-100 \%$ ethanol overnight at room temperature or longer at $4^{\circ} \mathrm{C}$. Embryos were then stained for bone and cartilage with alizarin red and alcian blue, respectively, as previously described ${ }^{71}$. The stained embryos were imaged in $50 \%$ glycerol similar to brightfield images.

\section{BMH-21 treatment}

E8.5 embryos were dissected with an intact yolk sac in Tyrode's buffer and cultured in preheated complete media containing 50\% DMEM-F12, 50\% rat serum, and $1 \mathrm{X}$ penicillin/streptomycin in roller culture bottles with $5 \% \mathrm{CO}_{2}, 5 \% \mathrm{O}_{2}$, and $90 \% \mathrm{~N}_{2}{ }^{70,72}$. After 60 minutes of equilibration, $4 \mu \mathrm{M}$ of BMH-21 (Sigma Aldrich, \#SML1183) was added to disrupt 
Pol I activity. Following 8 hours of incubation, embryos were fixed in $4 \%$ PFA/PBS at $4{ }^{\circ} \mathrm{C}$ overnight. TUNEL assay was performed following manufacturer's protocol (Roche) described below.

\section{View RNA and in-situ hybridization}

E9.5 and 10.5 embryos were harvested in $1 \mathrm{X}$ PBS/0.1\% DEPC and fixed in 4\% PFA in 1X PBS/0.1\% DEPC overnight at $4^{\circ} \mathrm{C}$. In situ hybridization for Col2al (plasmid obtained from Dr. Ralph Marcucio) was performed using standard protocols as previously described ${ }^{73}$. Control and mutant embryos were imaged at the same magnification on a Leica stereoscope using a Nikon DS-Ril camera. For ViewRNA, embryos were cryosectioned in RNAse free condition at a thickness of $10 \mu \mathrm{m}$. Sections were then air dried for 20 minutes and washed with $1 \mathrm{X}$ PBS. Sections were then dehydrated in $100 \%$ Ethanol for 5 minutes followed by antigen retrieval with pre-made target retrieval solution (RNAscope ${ }^{\circledR}$ Cat. No. 320850) or citric acid buffer pH 6 $(0.1 \mathrm{M}$ sodium citrate, $0.1 \mathrm{M}$ citric acid in water $)$ at $95^{\circ} \mathrm{C}$ for 12 minutes. Following proteinase treatment for 5 minutes at room temperature, sections were hybridized and stained per ViewRNA manual instructions (Invitrogen Catalog number: 88-19000).

\section{Quantification}

Embryo sections were imaged with an LSM-700 upright confocal laser scanning microscope. Prior to intensity quantification, $\mathrm{Z}$ stacks of mouse embryo sections stained with antibodies or RNA FISH were sum projected and a uniform background was subtracted based on a manually selected region near the neural tube. Nuclei were detected based on the DAPI signal using a twodimensional version of the algorithm used for the Click-IT OPP analysis above. Analysis was performed with the aid of the PyImageJ (https://github.com/imagej/pyimagej) interface to Fiji ${ }^{74}$ from Jupyter Notebooks (https://jupyter.org/) which are included in supplemental materials. For 
detection, mask diameters were 20 pixels with a threshold of $20 \%$ of the maximum intensity as before. Average intensity measurements were performed using the same mask diameter and twodimensional histograms and measurements were made of YFP signal vs. ViewRNA signal.

\section{OPP assay}

E8.5 and E9.5 Wnt1Cre;YFP embryos were cultured in 1:1000 OPP in DMEM-F12 culture media for 1 hour, followed by the Click-IT reaction per Click-iT ${ }^{\mathrm{TM}}$ Plus OPP Protein Synthesis Assay Kit Catalog \#C10457 manual instructions. MEFs treated with tamoxifen and DMSO were treated with 1:500 OPP for 3 hours, followed by the Click-IT reaction.

\section{Quantification}

Embryos were imaged with an LSM-700 upright confocal laser scanning microscope. OPP intensity levels were quantified using custom ImageJ (NIH, Bethesda, MD) plugins ${ }^{74}$. Detection of nuclear positions from the DAPI signal was performed using a maximum mask approach. This method detects the maximum intensity in the 3D image and then masks out a spheroidal region around it with an XY diameter of 25 pixels and $\mathrm{z}$ diameter of 15 slices. The maximum intensity is then found again and masked again repeatedly until there are no maximum pixels above a specified threshold. The threshold was set as $20 \%$ of the maximum DAPI intensity in the image. This algorithm does not find the nuclear positions perfectly, but it does provide a measurement proportional to the nuclear density. Average intensities in the YFP and OPP channels were then measured centered at the nuclear positions in a spheroid with an XY diameter of 20 pixels and a z diameter of 10 slices. This smaller measurement region ensures that slightly overlapping nuclei do not significantly influence the measurement. Two dimensional logarithmically binned histograms were made of the GFP signal (denoting the neural crest population) vs. the OPP signal. Those histograms showed clear positive and negative GFP populations allowing for 
manual drawing of rectangular gates for these populations followed by simple average intensity per cell calculations. In some cases, laser powers were adjusted during the signal acquisition and those values were corrected for in the measurement of the intensities.

\section{$\beta$-galactosidase staining}

E8.0-E9.5 embryos were collected and fixed in 2\% PFA/0.2\% glutaraldehyde in PBS for the following time duration: E8.5-E9.0 for 15 minutes and E9.5 for $30-45$ minutes at $4^{\circ} \mathrm{C}$. Embryos were then rinsed with PBS and stained according to manufacturer's protocol (Millipore \#BG-6B, \#BG-7-B, \#BG-8-C). Embryos were then fixed again in $4 \%$ PFA/PBS at $4{ }^{\circ} \mathrm{C}$ rocking overnight and washed in PBS for whole embryo brightfield imaging. For sections, embryos were rinsed and immersed into $30 \%$ sucrose/PBS overnight at $4^{\circ} \mathrm{C}$. The following day they were submerged into 1:1 30\% sucrose/OCT and then embedded in OCT and cryosectioned at a thickness of $10 \mu \mathrm{m}$. Sections were then imaged on an Axioplan 206 Std microscope with Micromanager 1.4, Win 10 software.

\section{Immunostaining}

Embryos were harvested at the desired developmental stages in 1X PBS and fixed in 4\%

PFA/1X PBS at $4{ }^{\circ} \mathrm{C}$ overnight with the exception of p53 staining which required fixation in $4 \%$ PFA/1X PBS at $4^{\circ} \mathrm{C}$ for 3 hours. For whole embryo staining, the embryos were then dehydrated through an ascending methanol series into $100 \%$ methanol and stored in $-20^{\circ} \mathrm{C}$ overnight.

Embryos then treated with 4:1:1 Methanol: DMSO: Hydrogen Peroxide and rehydrated through a descending methanol series into PBS. Embryos were then blocked with $2 \% \mathrm{BSA} / 2 \%$ goat serum prior to staining. For section-staining, the fixed embryos were cryosectioned transversely at 10 $\mu \mathrm{m}$ thickness, followed by blocking solution and staining as previously mentioned. For p53 staining, antigen retrieval was performed by immersing the sections in pre-warmed citric acid 
buffer (pH6, 0.1M sodium citrate, $0.1 \mathrm{M}$ citric acid in water) and incubated at $80-90^{\circ} \mathrm{C}$ for 30 minutes. Sections were then permeabilized with $0.5 \%$ TritonX-100 in PBS followed by $3 \%$ BSA blocking solution. Primary antibodies were used against the following proteins: Tcof1 (1:1000, Abcam\# ab65212), Sox9 (1:200, Abcam \# ab185966), TuJ1 (1:500, Covance Research products, \# MMS-435P), GFP (1:500, Life Technologies \#A6455), phospho-histone H3 (1:2000, Millipore \# 06-570) and p53 (1:100, Cell Signaling Technology \#2524S). The embryos and sections were counter-stained with DAPI (Sigma-Aldrich \#D9564) to visualize the nuclei. Embryos were imaged with an LSM-700 upright confocal laser scanning microscope. Confocal optical slices were collected and maximum-intensity projections of stacks were made with Zeiss LSM software.

\section{Quantification}

pHH3 measurements were performed similarly to the ViewRNA measurements. The DAPI channel was Gaussian blurred with a standard deviation of 5 pixels and the diameter for nuclear detection was 45 pixels with a threshold at $15 \%$ of the maximum intensity. The measurement diameter was 30 pixels. To determine the fraction of positive cells, the intensity of the brightest positive cells was measured as the average intensity of the four brightest cells in the image. This method assumes that there are at least 4 positive cells in each image which we have confirmed by visual inspection. The cutoff for positive cells was then set at $20 \%$ of that positive value and the fraction of cells above that cutoff was measured. Measurements are only reported for the YFP positive population. p53 measurements were performed identically to $\mathrm{pHH} 3$ but including all cells in the section. For statistical analysis, fluorescence intensities of Polr $1 a^{N K O / N K O}$, Polrlc ${ }^{N K O / N K O}$, and Tcofl $1^{N K O / N K O}$ were compared to Polrla ${ }^{N K O /+}, P_{0 l r l} c^{N K O /+}$, and Tcofl $1^{N K O /+}$, respectively. 


\section{TUNEL staining}

Following overnight 4\%PFA/PBS fixation, embryos were washed in 1X PBS and then dehydrated through an ascending methanol series into $100 \%$ methanol and stored at $-20^{\circ} \mathrm{C}$ overnight for wholemount staining. Embryos were then rehydrated through a descending methanol series into PBS. Alternatively, after fixation, embryos were placed into $30 \%$ sucrose/PBS overnight at $4{ }^{\circ} \mathrm{C}$ and then embedded in OCT for cryosectioning. Embryos and cryosections were permeabilized in $0.1 \%$ sodium citrate/PBT $(0.1 \%$ TritonX in $1 \mathrm{X}$ PBS $)$ for 10 minutes at room temperature. Samples were then washed in PBS and were then incubated with 1:19 TUNEL enzyme: buffer (Roche) at $37^{\circ} \mathrm{C}$ in the dark for 1-2 hours and then counter-stained with DAPI (Sigma-Aldrich \#D9564). Embryos were imaged with an LSM-700 upright confocal laser scanning microscope similar to the immunostaining.

\section{Quantification}

TUNEL measurements were performed similarly to the ViewRNA measurements. The fraction of positive cells was measured as the fraction of cells with an intensity above 10,000 units, a level corresponding approximately to the level of positive cells seen in the image. Measurements are reported only for the $\mathrm{YFP}+$ population.

\section{BrdU labelling}

To analyze cell proliferation, E8.5 pregnant mice were injected intraperitoneally with BrdU at $0.1 \mathrm{mg} / \mathrm{kg}$ of body weight. After 30 minutes of incubation, mice were sacrificed. For detection of BrdU-positive cells, transverse cryosections were incubated with $1 \mathrm{M} \mathrm{HCl}$ for 30 minutes at $37^{\circ} \mathrm{C}$ after immunostaining with pHH3 (Millipore \# 06-570, dilution 1:500), and following secondary antibody incubation. BrdU-positive cells were detected by immunostaining using a rat anti-BrdU antibody (Abcam, dilution 1:200). The number of BrdU+ and pHH3+ cells in neuroepithelium, 
mesoderm and endoderm were counted. Fluorescence microscopy was performed on a LSM5

PASCAL confocal microscope (Carl Zeiss).

\section{Cell sorting}

E9.5 and E10.5 embryos were dissected in Tyrode's buffer and yolk sacs were saved for genotyping. Control and mutant embryos positive for YFP were used for the cell sorting. The embryos were incubated at $37^{\circ} \mathrm{C}$ for 5 minutes with TypLE (Gibco) and vortexed for 10 seconds. This cycle of incubation and vortexing was repeated for a period of 15-20 minutes to obtain a single cell suspension, following which TypLE was quenched with fetal bovine serum. The cells were then centrifuged at $200 \mathrm{rcf}$ for 10 minutes. The supernatant was discarded, and the cells were resuspended in PBS. $1 \mu 1$ of $100 \mu \mathrm{g} / \mathrm{ml}$ propidium iodide was added to gate viable cells and the cells were sorted using a FACSMelody (BD Biosciences). YFP+ and YFP- live cells were immediately processed for RNA and protein isolation. Downstream analysis was performed after confirmation of genotypes.

\section{RNA isolation, cDNA preparation and qPCR}

RNA was extracted from sorted YFP+ and YFP- cells from control and mutant embryos using the Qiagen miRNeasy Micro Kit. RNA was tested for quality on the Agilent 2100 Bioanalyzer and only RNA samples with a RIN score greater than 8.0 were used. The Superscript III Kit (Invitrogen) was used to synthesize cDNA for qPCR using random hexamer primers. qPCR was performed on ABI7000 (Thermo QuantStudio 7) using Perfecta Sybr Green (Quantbio \# 95072250). Primers are listed in Supplemental Table 2. No template controls were run as negative

controls. $\Delta \Delta \mathrm{C}_{\mathrm{t}}$ method was used to calculate fold change. Student's t-test and ANOVA were used for statistical analysis and significance was determined based on $\mathrm{p}<0.05$.

\section{Silver staining}


2000 YFP+ cells and YFP- cells from controls and mutants were sorted using a FACSMelody

(BD Biosciences) sorter as mentioned previously. Cells were lysed at $4{ }^{\circ} \mathrm{C}$ for 30 minutes using $20 \mu \mathrm{l}$ of lysis buffer containing Tris $\mathrm{pH}$ 8.0, sodium chloride, sodium deoxycholate, SDS, NP-40, and protease inhibitor. Following lysis, the cells were centrifuged at $13,000 \mathrm{rpm}$ at $4{ }^{\circ} \mathrm{C}$ for 30 minutes. 1X Laemmli buffer (loading buffer) was added to the extracted protein and denatured at $95^{\circ} \mathrm{C}$ for 5 minutes. The protein was then loaded onto $4-20 \%$ gradient SDS-PAGE gels and run in an electrophoresis unit for 90 minutes at 90V. The gel was then stained using a Pierce Silver Stain kit (ThermoFisher Scientific, \#24612) following the manufacturer's instructions. Band intensities were measured as area under the curve using ImageJ.

\section{Mouse embryonic fibroblast derivation}

Mouse embryonic fibroblast cells (MEFs) were derived from E13.5 and E14.5 Polrla $a^{f l x f f l x}$,

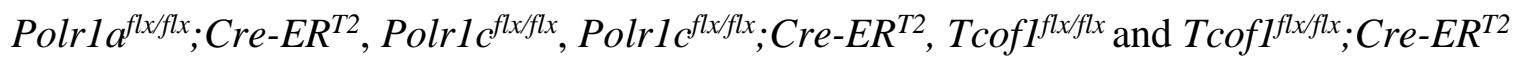
embryos as described previously ${ }^{75}$. Cells were cultured in a complete media containing DMEM, 30\% FBS, 1X L-Glutamine, 1X Non-essential amino acids, and 1X 2-mercaptoethanol and kept in passage for 3-5 generations. For deletion of Polrla, Polrla $a^{f l x f f l x} ; C r e-E R^{T 2}$ MEFs were treated with $5 \mu \mathrm{M}$ tamoxifen dissolved in DMSO, while Polr1c and Tcofl deletion was performed by treating Polr $1 c^{f l x f f l x} ; C r e-E R^{T 2}$ and Tcofl $1^{f l x f l x} ; C r e-E R^{T 2}$ MEFs with $1 \mu \mathrm{M}$ tamoxifen. Polrla $a^{f l x f f l x}$, Polrl $c^{f l x f l x}$ and Tcofl ${ }^{f l x f l x}$ MEFs treated with tamoxifen were used as controls. The treatment was performed for 24 hours and the cells were allowed to recover for 24 hours. All experiments were performed 48 hours post tamoxifen induction with three biological replicates of MEFs derived from three mutants as well as in three technical replicates. RNA isolation and qPCR were performed using the same approach and primers as above.

\section{Western blot}


MEFs treated with tamoxifen were lysed using lysis buffer and western blot was performed using standard protocols as described previously ${ }^{76}$. Protein quantity was estimated via a BCA assay. Antibodies used were p53 (1:500, Cell Signaling Technology, \#2524S), Rp15 (1:1000, Cell Signaling Technology, \#51345), Rpl11 (1:1000, Cell Signaling Technology, \#18163), Mdm2 (1:500, Cell Signaling Technology, \#86934) and y-Tubulin (1:1500, Millipore Sigma, \#T6557).

Western blots were imaged and quantified using a CLx-Scanner (Li-COR) and Odyssey

Software. For quantification, band intensities for Rp15, Rpl11, Mdm2 and p53 were compared to housekeeping control $\gamma$-Tubulin. Student's t-test was performed for statistical analysis.

\section{Immunoprecipitation}

MEFs were cultured on a T75 plate and harvested following tamoxifen treatment.

Immunoprecipitation was performed as previously described ${ }^{76}$. Briefly, the cells were homogenized in $500 \mu 1$ lysis buffer containing Tris $\mathrm{pH}$ 8.0, Sodium Chloride, SDS, Sodium deoxycholate, NP-40 and protease inhibitor. The homogenized mixture was then incubated with overhead rotation for 30 minutes at $4^{\circ} \mathrm{C}$ followed by centrifugation at $13,000 \mathrm{rpm}$ at $4^{\circ} \mathrm{C}$. The lysate was then divided into two tubes with of equal protein content, one for incubation with Normal Rabbit IgG and the other for incubation with Mdm2 antibody (Cell Signaling Technology, \#86934). $2 \mu \mathrm{g}$ of antibody was used per mg of protein for immunoprecipitation. $10 \%$ volume of the lysate used for immunoprecipitation was collected separately to be used for the control input lane for western blot analysis. The lysate-antibody mix was incubated at $4^{\circ} \mathrm{C}$ overnight with overhead rotation with a speed of $40 \mathrm{rpm}$. The following day pre-washed Dynabeads were incubated with the lysate-antibody mix at $4^{\circ} \mathrm{C}$ for 4 hours. The beads were then washed and eluted with $2 \mathrm{X}$ Laemmli buffer at $95^{\circ} \mathrm{C}$. The eluted protein was then used for SDSPAGE and western blot. The protein bands were detected using antibodies against p53 (Cell 
Signaling Technology, \#2524S), Rpl5 (Cell Signaling Technology, \#51345), Rpl11 (Cell

Signaling Technology, \#18163) and Mdm2 (Cell Signaling Technology, \#86934). For each biological replicate, cells from one T75 culture plate were used for immunoprecipitation. The experiment was performed in three biological and three technical replicates. For quantification, band intensity of Rpl5, Rpl11, and p53 were compared to Mdm2 in both control and mutant cells. Student's t-test was performed for statistical analysis.

\section{Single cell RNA sequencing}

\section{Tissue collection}

6 Mef2c-F1ON-LacZ ${ }^{67}$ and 6 Wnt1-Cre;RosaeYFP ${ }^{29,37,69}$ mice were collected at E8.5. Cranial tissues were manually dissected and incubated in $0.25 \%$ Trypsin+EDTA in a $37^{\circ} \mathrm{C}$ water bath for 1 minute and dissociated through gentle repetitive pipetting about 10 times. The tube was then incubated again in a $37^{\circ} \mathrm{C}$ water bath for another minute prior to the addition of cold FBS to block further reaction with Trypsin activity. Samples were then centrifuged at $1600 \mathrm{rcf}$ at $4^{\circ} \mathrm{C}$ for 15 minutes. The supernatant was discarded and the cells were resuspended in $200 \mu 1 \mathrm{PBS}+2 \%$ FBS. Cells were centrifuged again and resuspended in $40 \mu 1$ PBS. Genotyping was performed after cell dissociation which indicated that 3 out of the 6 Mef2c-F1ON-LacZ embryos were LacZ positive and that 4 out of the 6 Wnt1-Cre;RosaeYFP embryos were YFP positive.

\section{Processing and Sequencing}

Dissociated cells were assessed for concentration and viability using a Luna-FL cell counter (Logos Biosystems). The cells were confirmed to have at least 70\% viability and 12,000-15,000 cells per sample were loaded on a Chromium Single Cell Controller (10x Genomics). Libraries were prepared using the Chromium Next GEM Single Cell 3' Library \& Gel Bead Kit v3.1 (10x Genomics) according to manufacturer's directions. Resulting short fragment libraries were 
checked for quality and quantity using a Bioanalyzer (Agilent) and Qubit Fluorometer

(ThermoFisher). Libraries were pooled at equal molar concentrations and sequenced on an

Illumina NovaSeq 6000 S1 flow cell with the following paired read lengths: 28 bp Read1, 8 bp

I7 Index and 98 bp Read2.

Data processing

Raw sequencing data was processed using Cell Ranger (v3.0.0, 10x Genomics) to generate genelevel counts for each cell in each sample. Genes with counts in less than three cells were removed from the dataset. Mitochondrial percentages and feature count distribution were used as criteria for cell quality control. The percent mitochondria threshold was set to keep $75 \%$ of cells of the Mef2c-F1ON-LacZ sample (mito $\leq 10.93 \%$ ). The same threshold was applied to the Wnt1Cre;RosaeYFP sample, keeping $86 \%$ of the cells. In addition, cells with feature counts of > 10,000 or $<500$ were also excluded from the analysis. The final dataset used for analysis consisted of 21,190 cells (12,498 cells for Wnt1-Cre;RosaeYFP and 8,692 for Mef2c-F10NLacZ) and 29,041 genes and is available at the Gene Expression Omnibus (accession no. GSE168351).

The Seurat package (v3.1.1) ${ }^{77}$ was used to normalize data via the SCTransform method ${ }^{78}$. Mitochondrial percentage was regressed out during normalization. For clustering, 3000 highly variable genes were selected, and the first 46 principal components based on those genes were used to identify 7 clusters at a resolution of 0.05 using the shared nearest neighbor method. The identities of clusters were determined by the differential gene expression of classic markers for each tissue type. Neuroepithelial cells were identified by high expression of classic markers, Sox2 and Sox1. Neural crest cell reporters, LacZ and pEYFP, and Sox 10 were used to cluster NCC. Embryonic blood cells were clustered based on Hba-x expression and endothelial cells 
based on $K d r$ expression. $C d h l$ expression was used to identify non-neural ectoderm and $T b x l$ expression was used to cluster endodermal and mesodermal cells. Data was visualized in reduced dimensionality using UMAP.

The expression value for each gene was standardized by subtracting the gene's mean expression and dividing by its standard deviation. For instance, a value of -1 would imply that the value is one standard deviation below the mean expression for that specific gene.

\section{Acknowledgments}

The authors thank members of the Trainor lab and Dr Robb Krumlauf for their insights and discussions. We acknowledge Rodney McCay, Lacey Ellington and the Stowers Institute ES Cell and Transgenic Core for generating the Polrl $c^{\beta g e o}$ and Polrl $d^{\beta g e o}$ mice, and Madelaine Gogol for bioinformatic support. We also thank Mark Miller for illustrating Figure S12. All data needed to evaluate the conclusions in this study are present in the main text, the supplementary materials, and/or the Gene Expression Omnibus (accession no. GSE168351).

\section{Funding}

Stowers Institute for Medical Research (P.A.T)

Kirschstein-NRSA F31 predoctoral fellowship (DE027860) from the National Institute for Dental and Craniofacial Research (K.T.F)

American Association for Anatomy Post-Doctoral Fellowship (A.A.)

American Association for Anatomy Post-Doctoral Fellowship (S.D.)

Kirschstein-NRSA F31 predoctoral fellowship (DE023017) from the National Institute for Dental and Craniofacial Research (K.E.N.W)

\section{Author contributions:}

Conceptualization: PAT, KTF, KENW, AA 
Methodology: KTF, KENW, SD, AA, ELM, RZ, AF, DS, MES, SS, GB, LL, DT, JU, MC, PAT

Investigation: KTF, KENW, SD, AA, ELM, RZ, AF, DS, MES, SS, GB, LL, DT, JU, MC, PAT

Visualization: KTF, KENW, SD, AA, ELM, RZ, AF, DS, MES, SS, GB, LL, DT, JU, MC, PAT

Funding acquisition: PAT, KTF, AA, KENW, SD

Project administration: PAT

Supervision: PAT

Resources: RS, JD, MJD

Writing - original draft: KTF, KENW, SD

Writing - review \& editing: KTF, KENW, SD, AA, ELM, RZ, SF, DS, RS, JD, MJD, PAT

Competing interests: Authors declare that they have no competing interests. 


\section{References}

1. Trainor, P. A. \& Merrill, A. E. Ribosome biogenesis in skeletal development and the pathogenesis of skeletal disorders. Biochim. Biophys. Acta - Mol. Basis Dis. 1842, 769-778 (2014).

2. Jorgensen, P. et al. A dynamic transcriptional network communicates growth potential to ribosome synthesis and critical cell size. Genes Dev. 18, 2491-2505 (2004).

3. Chaillou, T., Kirby, T. J. \& Mccarthy, J. J. Ribosome Biogenesis: Emerging Evidence for a Central Role in the Regulation of Skeletal Muscle Mass. J. Cell. Physiol. 229, 1584-1594 (2014).

4. Kirn-Safran, C. B. et al. Global growth deficiencies in mice lacking the ribosomal protein HIP/RPL29. Dev. Dyn. 236, 447-460 (2007).

5. Thomas, G. An encore for ribosome biogenesis in the control of cell proliferation. vol. 2 Www.nature.com/ncb (2000).

6. Laferté, A. et al. The transcriptional activity of RNA polymerase I is a key determinant for the level of all ribosome components. Genes Dev. 20, 2030-2040 (2006).

7. Chédin, S. et al. Is ribosome synthesis controlled by Pol I transcription? Cell Cycle 6, 11-15 (2007).

8. Misiaszek, A. D. et al. Cryo-EM structures of human RNA polymerase I. http://biorxiv.org/lookup/doi/10.1101/2021.05.31.446457 (2021) doi:10.1101/2021.05.31.446457. 
9. Polikanov, Y. S., Melnikov, S. V., Söll, D. \& Steitz, T. A. Structural insights into the role of rRNA modifications in protein synthesis and ribosome assembly. Nat. Struct. Mol. Biol. 22, $342-344(2015)$.

10. Warner, J. R. The economics of ribosome biosynthesis in yeast. Trends Biochem. Sci. 24, 437-440 (1999).

11. Sulima, S. O., Kampen, K. R. \& De Keersmaecker, K. Cancer Biogenesis in Ribosomopathies. Cells 8, 229 (2019).

12. Danilova, N. \& Gazda, H. T. Ribosomopathies: how a common root can cause a tree of pathologies. Dis. Model. Mech. 8, 1013-1026 (2015).

13. Yelick, P. C. \& Trainor, P. A. Ribosomopathies: Global process, tissue specific defects. Rare Dis. 3, e1025185-e1025185 (2015).

14. Mills, E. W. \& Green, R. Ribosomopathies: There's strength in numbers. Science 358, eaan2755-eaan2755 (2017).

15. Weaver, K. N. et al. Acrofacial dysostosis, cincinnati type, a mandibulofacial dysostosis syndrome with limb anomalies, is caused by POLR1A dysfunction. Am. J. Hum. Genet. 96, 765-774 (2015).

16. Dauwerse, J. G. et al. Mutations in genes encoding subunits of RNA polymerases i and III cause Treacher Collins syndrome. Nat. Genet. 43, 20-22 (2011).

17. Noack Watt, K. E., Achilleos, A., Neben, C. L., Merrill, A. E. \& Trainor, P. A. The Roles of RNA Polymerase I and III Subunits Polr1c and Polr1d in Craniofacial Development and in Zebrafish Models of Treacher Collins Syndrome. PLoS Genet. 12, (2016).

18. Terrazas, K., Dixon, J., Trainor, P. A. \& Dixon, M. J. Rare syndromes of the head and face: mandibulofacial and acrofacial dysostoses. Wiley Interdiscip. Rev. Dev. Biol. 6, (2017). 
19. Trainor, P. A., Dixon, J. \& Dixon, M. J. Treacher Collins syndrome: etiology, pathogenesis and prevention. Eur. J. Hum. Genet. EJHG 17, 275-283 (2009).

20. Gonzales, B. et al. The Treacher Collins syndrome (TCOF1) gene product is involved in pre-rRNA methylation. Hum. Mol. Genet. 14, 2035-2043 (2005).

21. Valdez, B. C., Henning, D., So, R. B., Dixon, J. \& Dixon, M. J. The Treacher Collins syndrome (TCOF1) gene product is involved in ribosomal DNA gene transcription by interacting with upstream binding factor. Proc. Natl. Acad. Sci. U. S. A. 101, 10709-10714 (2004).

22. Donati, G. et al. The balance between rRNA and ribosomal protein synthesis up- and downregulates the tumour suppressor p53 in mammalian cells. Oncogene 30, 3274-3288 (2011).

23. Scala, F. et al. Direct relationship between the level of p53 stabilization induced by rRNA synthesis-inhibiting drugs and the cell ribosome biogenesis rate. Oncogene 35, 977989 (2016).

24. Walker-Kopp, N. et al. Treacher Collins syndrome mutations in Saccharomyces cerevisiae destabilize RNA polymerase I and III complex integrity. Hum. Mol. Genet. 26, 4290-4300 (2017).

25. Sanchez, E. et al. POLR1B and neural crest cell anomalies in Treacher Collins syndrome type 4. Genet. Med. 22, 547-556 (2020).

26. You, X. et al. Neural circular RNAs are derived from synaptic genes and regulated by development and plasticity. Nat. Neurosci. 18, 603-610 (2015).

27. Qian, J., Lavker, R. M. \& Tseng, H. Mapping ribosomal RNA transcription activity in the mouse eye. Dev. Dyn. 235, 1984-1993 (2006). 
28. Cui Chunhua \& Tseng Hung. Estimation of ribosomal RNA transcription rate in situ.

134-138 https://www.future-science.com/doi/pdf/10.2144/04361RR04 (2004)

doi:10.2144/04361RR04.

29. Echelard, Y., Vassileva, G. \& McMahon, A. P. Cis-acting regulatory sequences

governing Wnt-1 expression in the developing mouse CNS. Development 120, 2213-2213 (1994).

30. Liu, J., Xu, Y., Stoleru, D. \& Salic, A. Imaging protein synthesis in cells and tissues with an alkyne analog of puromycin. doi:10.1073/pnas.1111561108/-/DCSupplemental.

31. Colis, L. et al. DNA intercalator BMH-21 inhibits RNA polymerase I independent of DNA damage response. Oncotarget 5, 4361-4369 (2014).

32. Laurence Florens, M. P. W. Proteomic Analysis by Multidimensional Protein Identification Technology. Methods Mol Biol 159-175-159-175 (2006) doi:10.1385/1-59745026-X:159.

33. Washburn, M. P., Wolters, D. \& Yates, J. R. Large-scale analysis of the yeast proteome by multidimensional protein identification technology. Nat. Biotechnol. 19, 242-247 (2001).

34. Isaac, C. et al. Characterization of the Nucleolar Gene Product, Treacle, in Treacher Collins Syndrome. vol. 11 3061-3071 (2000).

35. Dixon, J. et al. Tcof1/Treacle is required for neural crest cell formation and proliferation deficiencies that cause craniofacial abnormalities. Proc. Natl. Acad. Sci. U. S. A. 103, 1340313408 (2006).

36. Conley, Z. R. et al. A quantitative method for defining high-arched palate using the Tcof1+/- mutant mouse as a model. Dev. Biol. 415, 296-305 (2016). 
37. Brault, V. et al. Inactivation of the $(\beta)$-catenin gene by Wnt1-Cre-mediated deletion results in dramatic brain malformation and failure of craniofacial development. Development 128, 1253-1253 (2001).

38. Ng, L.-J. et al. SOX9 Binds DNA, Activates Transcription, and Coexpresses with Type II Collagen during Chondrogenesis in the Mouse. Dev. Biol. 183, 108-121 (1997).

39. Fumagalli, S. \& Thomas, G. The Role of p53 in Ribosomopathies. Semin. Hematol. 48, 97-105 (2011).

40. Jones, N. C. et al. Prevention of the neurocristopathy Treacher Collins syndrome through inhibition of p53 function. Nat. Med. 14, 125-133 (2008).

41. Chevallet, M., Luche, S. \& Rabilloud, T. Silver staining of proteins in polyacrylamide gels. Nat. Protoc. 1, 1852-1858 (2006).

42. Haupt, Y., Maya, R., Kazaz, A. \& Oren, M. Mdm2 promotes the rapid degradation of p53. Nature 387, 296-299 (1997).

43. Lohrum, M. A. E., Ludwig, R. L., Kubbutat, M. H. G., Hanlon, M. \& Vousden, K. H. Regulation of HDM2 activity by the ribosomal protein L11. Cancer Cell 3, 577-587 (2003).

44. Liu, Y., Deisenroth, C. \& Zhang, Y. RP-MDM2-p53 Pathway: Linking Ribosomal Biogenesis and Tumor Surveillance. Trends Cancer 2, 191-204 (2016).

45. Pestov, D. G., Strezoska, Z. \& Lau, L. F. Evidence of p53-dependent cross-talk between ribosome biogenesis and the cell cycle: effects of nucleolar protein Bop1 on $\mathrm{G}(1) / \mathrm{S}$ transition. Mol. Cell. Biol. 21, 4246-4255 (2001).

46. Prakash, V. et al. Ribosome biogenesis during cell cycle arrest fuels EMT in development and disease. Nat. Commun. 10, (2019). 
47. Engel, C., Sainsbury, S., Cheung, A. C., Kostrewa, D. \& Cramer, P. RNA polymerase I structure and transcription regulation. Nature 502, 650-655 (2013).

48. Calo, E. et al. Tissue-selective effects of nucleolar stress and rDNA damage in developmental disorders. Nature 554, 112-117 (2018).

49. Neben, C. L., Tuzon, C. T., Mao, X., Lay, F. D. \& Merrill, A. E. FGFR2 mutations in bent bone dysplasia syndrome activate nucleolar stress and perturb cell fate determination. Hum. Mol. Genet. 26, 3253-3270 (2017).

50. Lessard, F., Brakier-Gingras, L. \& Ferbeyre, G. Ribosomal Proteins Control Tumor Suppressor Pathways in Response to Nucleolar Stress. BioEssays 41, 1800183 (2019).

51. Le Goff, S. et al. p53 activation during ribosome biogenesis regulates normal erythroid differentiation. Blood 137, 89-102 (2021).

52. Iadevaia, V., Zhang, Z., Jan, E. \& Proud, C. G. mTOR signaling regulates the processing of pre-rRNA in human cells. Nucleic Acids Res. 40, 2527-2539 (2012).

53. Stefanovsky, V. Y. et al. An Immediate Response of Ribosomal Transcription to Growth Factor Stimulation in Mammals Is Mediated by ERK Phosphorylation of UBF. Mol. Cell 8, 1063-1073 (2001).

54. Chan, J. C. et al. AKT Promotes rRNA Synthesis and Cooperates with c-MYC to Stimulate Ribosome Biogenesis in Cancer. Sci. Signal. 4, ra56-ra56 (2011).

55. Piazzi, M., Bavelloni, A., Gallo, A., Faenza, I. \& Blalock, W. L. Signal Transduction in Ribosome Biogenesis: A Recipe to Avoid Disaster. Int. J. Mol. Sci. 20, 2718-2718 (2019).

56. Panoutsopoulos, A. A. et al. Pak1ip1 Loss-of-Function Leads to Cell Cycle Arrest, Loss of Neural Crest Cells, and Craniofacial Abnormalities. Front. Cell Dev. Biol. 8, (2020). 
57. Genuth, N. R. \& Barna, M. The Discovery of Ribosome Heterogeneity and Its

Implications for Gene Regulation and Organismal Life. Mol. Cell 71, 364-374 (2018).

58. Chau, K. F. et al. Downregulation of ribosome biogenesis during early forebrain development. eLife 7, e36998-e36998 (2018).

59. Woolnough, J. L., Atwood, B. L., Liu, Z., Zhao, R. \& Giles, K. E. The regulation of rRNA gene transcription during directed differentiation of human embryonic stem cells. PLoS ONE 11, (2016).

60. Zhang, Q., Shalaby, N. A. \& Buszczak, M. Changes in rRNA transcription influence proliferation and cell fate within a stem cell lineage. Science 343, 298-301 (2014).

61. Parks, M. M. et al. Variant ribosomal RNA alleles are conserved and exhibit tissuespecific expression. http://advances.sciencemag.org/ (2018).

62. Salim, D. et al. DNA replication stress restricts ribosomal DNA copy number. PLoS

Genet. 13, e1007006-e1007006 (2017).

63. Ali, S. A. et al. A RUNX2-HDAC1 co-repressor complex regulates rRNA gene expression by modulating UBF acetylation. J. Cell Sci. 125, 2732-2739 (2012).

64. Watt, K. E. N., Neben, C. L., Hall, S., Merrill, A. E. \& Trainor, P. A. Tp53-dependent and independent signaling underlies the pathogenesis and possible prevention of Acrofacial Dysostosis-Cincinnati type. Hum. Mol. Genet. 27, 2628-2643 (2018).

65. Kranz, A. et al. An improved Flp deleter mouse in C57Bl/6 based on Flpo recombinase. Genes. N. Y. N 2000 48, 512-520-512-520 (2010).

66. Dixon, J., Fässler, R. \& Dixon, M. J. Increased levels of apoptosis in the prefusion neural folds underlie the craniofacial disorder, Treacher Collins syndrome. vol. 9 1473-1480 (2000). 
67. Aoto, K. et al. Mef2c-F10N enhancer driven $\beta$-galactosidase (LacZ) and Cre recombinase mice facilitate analyses of gene function and lineage fate in neural crest cells. Dev. Biol. $\mathbf{4 0 2}$, 3-16 (2015).

68. Jiang, X., Rowitch, D. H., Soriano, P., McMahon, A. P. \& Sucov, H. M. Fate of the mammalian cardiac neural crest. Development 127, 1607-1607 (2000).

69. Chai, Y. et al. Fate of the mammalian cranial neural crest during tooth and mandibular morphogenesis. Development 127, 1671-1671 (2000).

70. Sakai, D., Dixon, J., Achilleos, A., Dixon, M. \& Trainor, P. A. Prevention of Treacher Collins syndrome craniofacial anomalies in mouse models via maternal antioxidant supplementation. Nat. Commun. 7, (2016).

71. Dennis, J. F. et al. Mutations in Hedgehog acyltransferase (Hhat) perturb Hedgehog signaling, resulting in severe acrania-holoprosencephaly-agnathia craniofacial defects. PLoS Genet. 8, e1002927-e1002927 (2012).

72. Munoz, W. \& Trainor, P. Mouse Embryo Culture for the Study of Neural Crest Cells. in Methods in molecular biology (Clifton, N.J.) vol. 1976 107-119 (2019).

73. Behringer Richard, Gertsenstein Marina, Nagy Vintersten, \& Nagy Andras. Manipulating the Mouse Embryo: A Laboratory Manual, Fourth Edition. (2014).

74. Schindelin, J. et al. Fiji: an open-source platform for biological-image analysis. Nat. Methods 9, 676-682 (2012).

75. Xu, J. Preparation, Culture, and Immortalization of Mouse Embryonic Fibroblasts. Curr. Protoc. Mol. Biol. 70, 28.1.1-28.1.8 (2005). 
76. Dash, S., Bhatt, S., Falcon, K. T., Sandell, L. L. \& Trainor, P. A. Med23 Regulates Sox9 Expression during Craniofacial Development. J. Dent. Res. 00220345209691090022034520969109 (2020) doi:10.1177/0022034520969109.

77. Satija, R., Farrell, J. A., Gennert, D., Schier, A. F. \& Regev, A. Spatial reconstruction of single-cell gene expression data. Nat. Biotechnol. 33, 495-502 (2015).

78. Hafemeister, C. \& Satija, R. Normalization and variance stabilization of single-cell RNAseq data using regularized negative binomial regression. Genome Biol. 20, 296-296 (2019).

Data and materials availability: Original data underlying this manuscript can be accessed from the Stowers Original Data Repository at http://www.stowers.org/research/publications/LIBPB1604.

\section{Supplementary Materials}

Materials and Methods

Figs. S1 to S10

Tables S1 to S2 


\section{A 475 pre-rRNA}

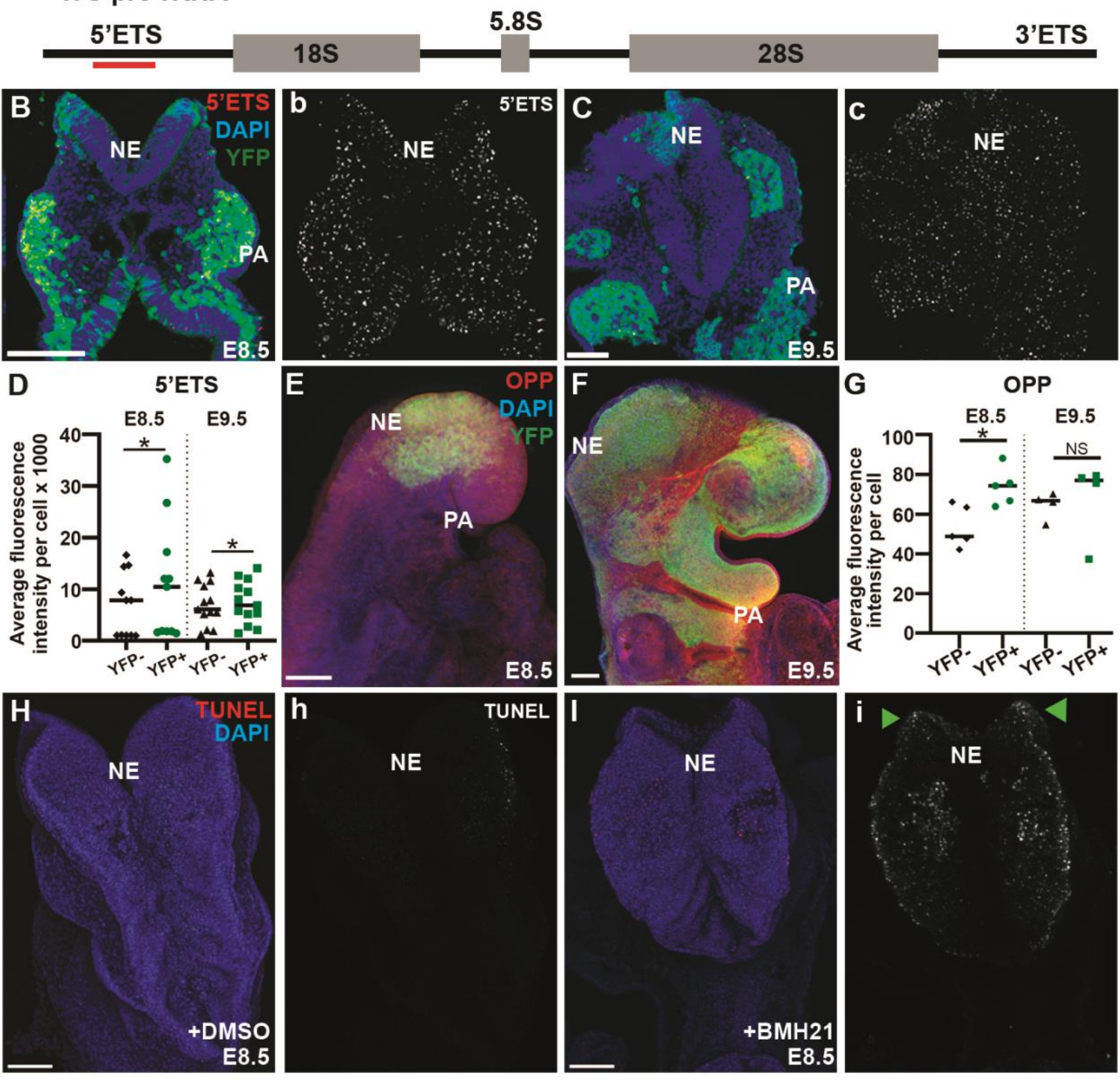

Fig. 1. Elevated levels of rRNA synthesis in NCC results in high sensitivity to disruptions in Pol I.

(A) Diagram of 47S pre-rRNA showing the 5' External Transcribed Spacer (ETS, red underline), 18S, 5.8S and 28S rRNA components and 3'ETS. (B, C) Fluorescence in situ hybridization using ViewRNA ${ }^{\mathrm{TM}}$ for the $5^{\prime} E T S$ region of the 47S pre-rRNA in transverse sections of wild-type Wnt1-Cre;ROSAeYFP embryos. At E8.5, 5'ETS expression (red in B, white in b) is significantly higher in NCC (YFP+) compared to non-NCC (YFP-). At E9.5, 5'ETS expression remains only slightly higher in NCC (C, c). 
Quantification in (D). (E, F) Nascent protein synthesis was analyzed via OPP incorporation in wild-type Wnt1-Cre;ROSAeYFP embryos. (E) NCC (YFP+) have elevated OPP staining at E8.5. (F) OPP staining is comparable between NCC and non-NCC by E9.5. Quantification in (G). (H, I) Disruption of Pol I transcription in wild-type embryos at E8.5 with Pol I inhibitor BMH-21 results in increased TUNEL positive cells (red in (H) and (I), white in (h) and (i)) in the neuroepithelium, including the dorsal neuroepithelium where NCC progenitors are located. * indicates $\mathrm{p}<0.05$ using the Paired t-test. Abbreviations: NE, neuroepithelium; NS, not significant; PA, pharyngeal arches. Scale bar $=100 \mu \mathrm{m}$. 


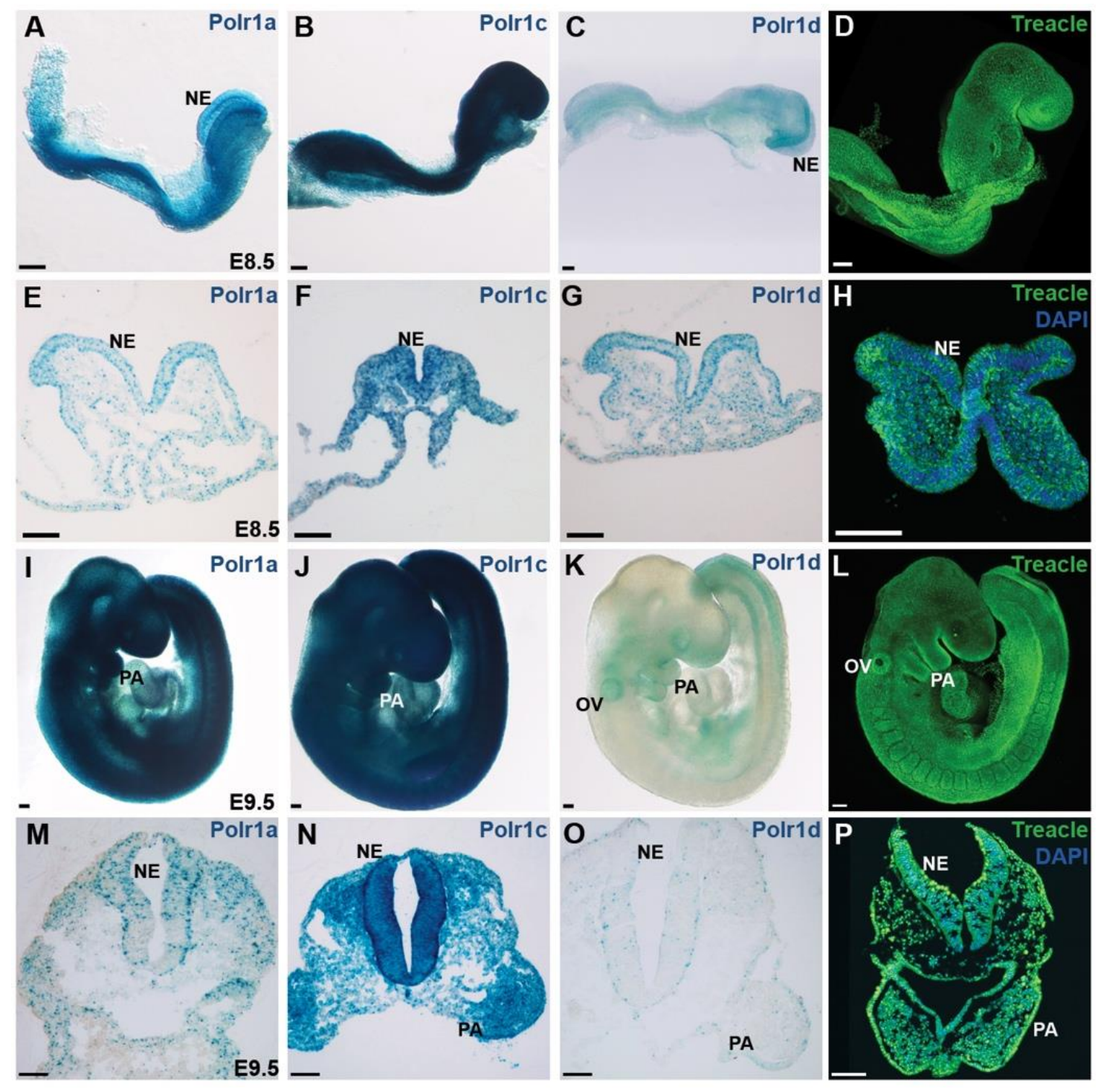

Fig. 2. Pol I subunits and associated factor Treacle are broadly expressed during mouse

embryogenesis. (A-C) Broad expression of Pol I subunits Polrla, Polrlc, and Polrld as observed by LacZ staining in E8.5 embryos. (E-G) Transverse sections through the cranial region indicate high levels of Polrla (E), Polrlc (F) and Polrld (G) expression in the neuroepithelium. (I-K) At E9.5, Polrla and Polrlc remain broadly expressed (I, J) while Polrld is expressed specifically in the pharyngeal arches, otic vesicle and somites (K). Transverse sections through the cranial region at E9.5 indicate high expression of Polr1a (M), Polr1c (N) and Polr1d (O) in the neuroepithelium and pharyngeal arches. (D,H,L,P) Immunostaining for Treacle reveals broad expression in whole-embryo and transverse sections 
bioRxiv preprint doi: https://doi.org/10.1101/2021.09.22.461379; this version posted September 22, 2021. The copyright holder for this preprint (which was not certified by peer review) is the author/funder, who has granted bioRxiv a license to display the preprint in perpetuity. It is made available under aCC-BY-NC-ND 4.0 International license.

of E8.5 and E9.5 embryos, with dynamic elevated levels in the neuroepithelium $(\mathrm{H}, \mathrm{P})$. Abbreviations:

NE, neuroepithelium, OV, otic vesicle; PA, pharyngeal arches. Scale bar $=100 \mu \mathrm{m}$ 
A

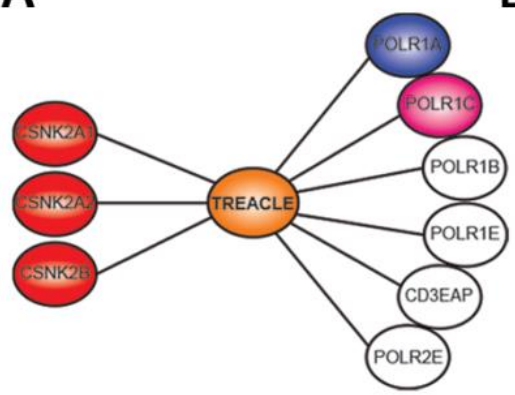

B

\begin{tabular}{|lcccc|}
\hline Phenotype & Tcof1 $^{+/-}$ & Tcof1 $^{+l-} ;$ Polr1a & Tcof1 \\
\hline $\begin{array}{l}\text { Craniofacial } \\
\text { hypoplasia }\end{array}$ & $53(100 \%)$ & $17(100 \%)$ & $17(100 \%)$ & $15(100 \%)$ \\
Exencephaly & $7(13.2 \%)$ & $13(76.5 \%)$ & $15(88.2 \%)$ & $11(73.3 \%)$ \\
Thoracoschisis & $0(0 \%)$ & $7(41.2 \%)$ & $4(23.5 \%)$ & $9(60.0 \%)$ \\
Digit/limb defects & $0(0 \%)$ & $6(35.3 \%)$ & $3(17.6 \%)$ & $4(26.7 \%)$ \\
\hline
\end{tabular}
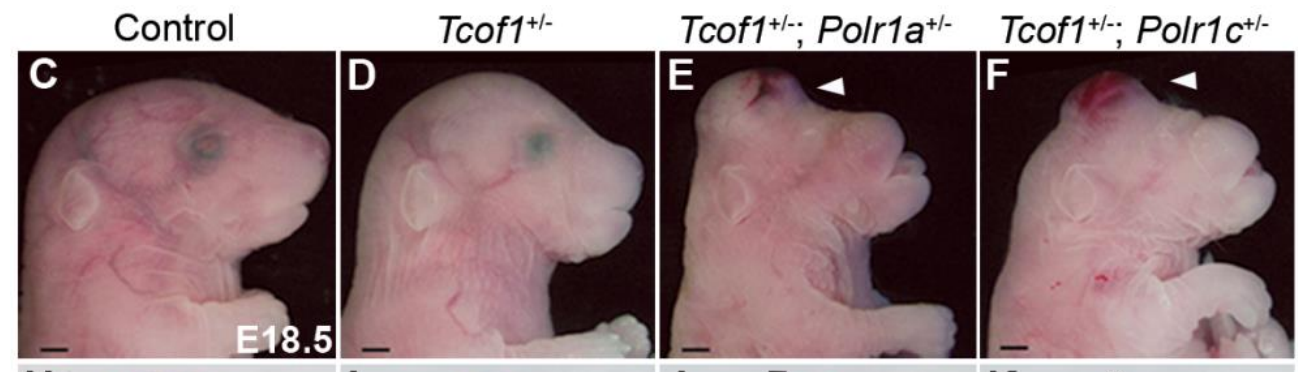

Tcof1 $1^{+/-;}$Polr1d ${ }^{+/-}$
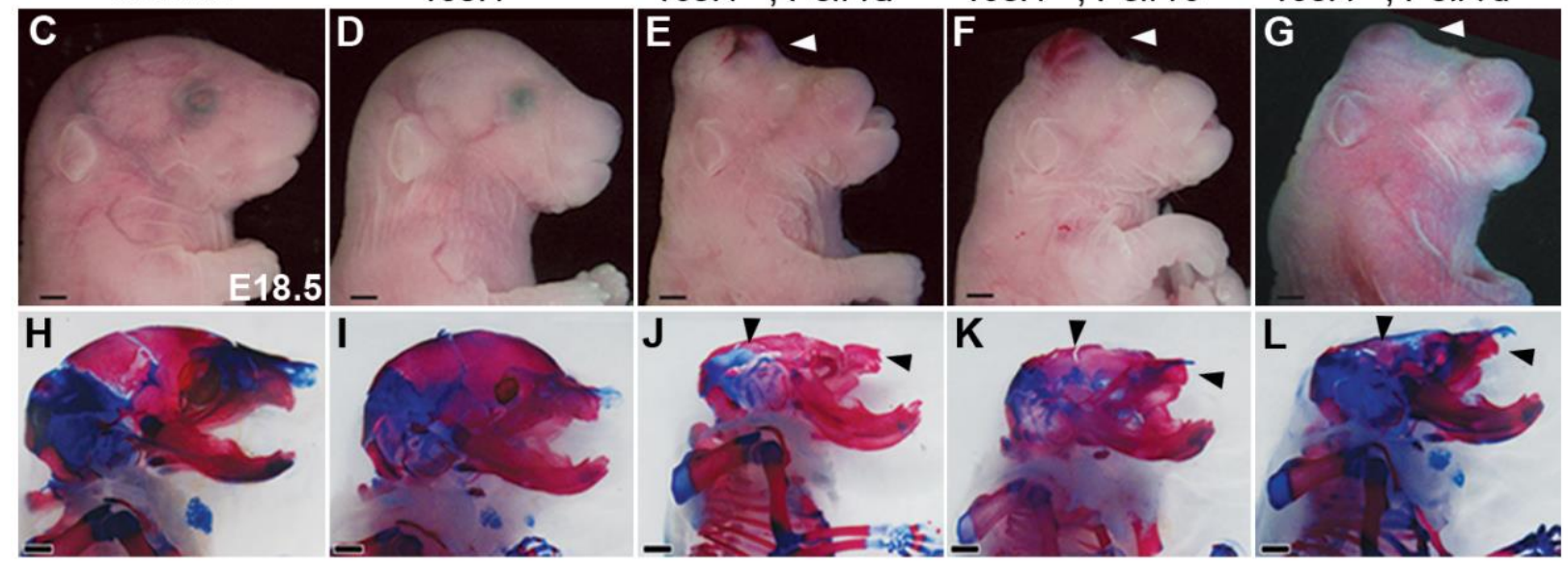

Fig. 3. Tcof1 and Pol I subunits genetically and physically interact, affecting craniofacial

development. (A) MudPIT analysis for Treacle-binding proteins recognizes known biding proteins such as Casein kinase II proteins as well as Pol I protein subunits including POLR1A and POLR1C.

(B)

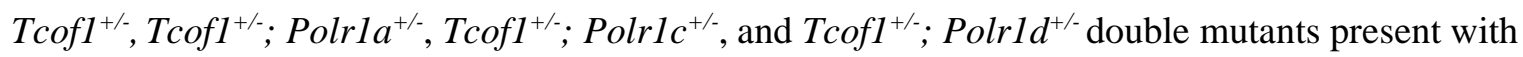
developmental defects with variable penetrance. Table indicates the number of embryos observed with a phenotype. The percentages of the total number of mutants observed are indicated in parentheses. (C-G) Brightfield images of $\mathrm{TcofI}^{+/} ;$Polrla $^{+/}, \mathrm{TcofI}^{+/} ; \mathrm{PolrlC}^{+/}$, and $\mathrm{TcofI}^{+/} ; \mathrm{Polrld}^{+/-}$embryos indicate that these double heterozygous mutants exhibit more severe craniofacial defects compared to $T c o f 1^{+-}$mutants alone. (H-L) Alizarin red and alcian blue staining for bone and cartilage, respectively, reveals hypoplastic cartilage and/or bone and craniofacial anomalies including smaller maxilla, flattened skulls, and exencephaly in double mutant embryos (J-L) compared to Tcof1 $1^{+/-}$mutants (I) alone. Scale bar $=500 \mu \mathrm{m}$. 


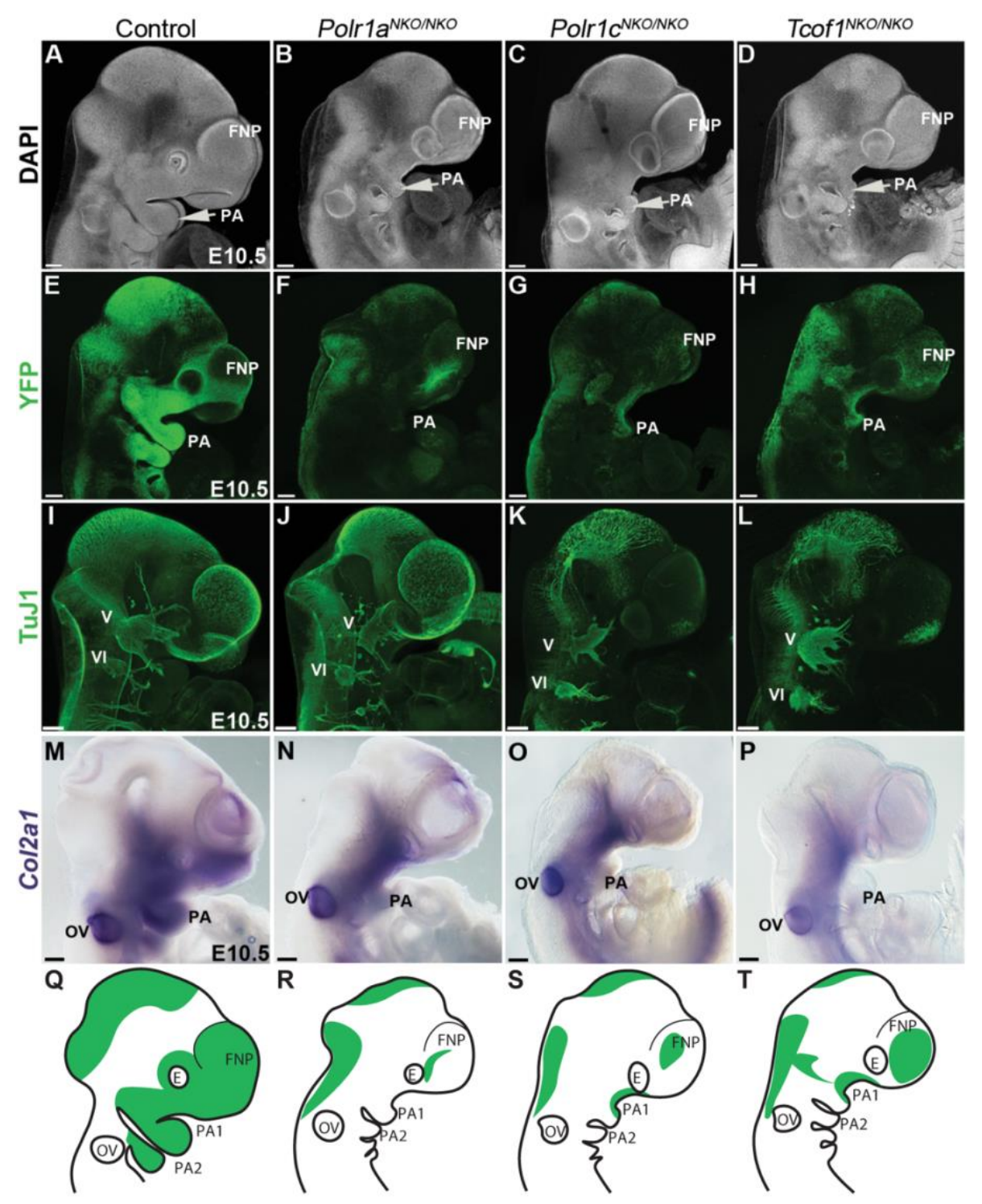

Fig. 4. Polr1a, Polr1c, and Tcof1 are required for NCC and craniofacial development in mice. (A-

D) DAPI staining at E10.5 shows hypoplastic pharyngeal arches (white arrow) and frontonasal prominences in Polrla $a^{N K O / N K O}$, Polrl $c^{N K O / N K O}$, and Tcof1 $1^{N K O / N K O}$ embryos compared to control embryos. (E-H) Polrla $a^{N K O / N K O}$, Polrl $c^{N K O / N K O}$, and Tcofl $1^{N K O / N K O}$ were bred into the background of ROSAeYFP mice to label the NCC lineage with YFP. YFP staining indicates fewer NCC in the pharyngeal arches and frontonasal prominences in Polr $1 a^{N K O / N K O}, P_{0} \operatorname{lr} 1 c^{N K O / N K O}$, and Tcof1 ${ }^{\text {NKO/NKO }}$ embryos. (I-L) Neuron-specific class III $\beta$-tubulin (TuJ1) staining indicates NCC 
differentiation to neurons and glia is disrupted in Polrla $a^{N K O / N K O}, P_{0} l r l c^{N K O / N K O}$, and Tcof1 ${ }^{\text {NKO/NKO }}$ embryos. The trigeminal (V) nerve ganglia are hypoplastic in all mutants. (M-P) In situ hybridization for chondrogenesis marker Col2al shows reduced expression especially within the pharyngeal arches in Polrla ${ }^{N K O / N K O}, P o l r 1 c^{N K O / N K O}$, and Tcof1 $1^{N K O / N K O}$ embryos. (Q-T) Schematic figures depicting hypoplastic pharyngeal arches and frontonasal prominences as well as decreased NCC (green) in mutants versus controls. Abbreviations: FNP, Frontonasal prominence; OV, Otic vesicle; PA, pharyngeal arches. Scale bar $=200 \mu \mathrm{m}$. 
bioRxiv preprint doi: https://doi.org/10.1101/2021.09.22.461379; this version posted September 22, 2021. The copyright holder for this preprint (which was not certified by peer review) is the author/funder, who has granted bioRxiv a license to display the preprint in perpetuity. It is made available under aCC-BY-NC-ND 4.0 International license.

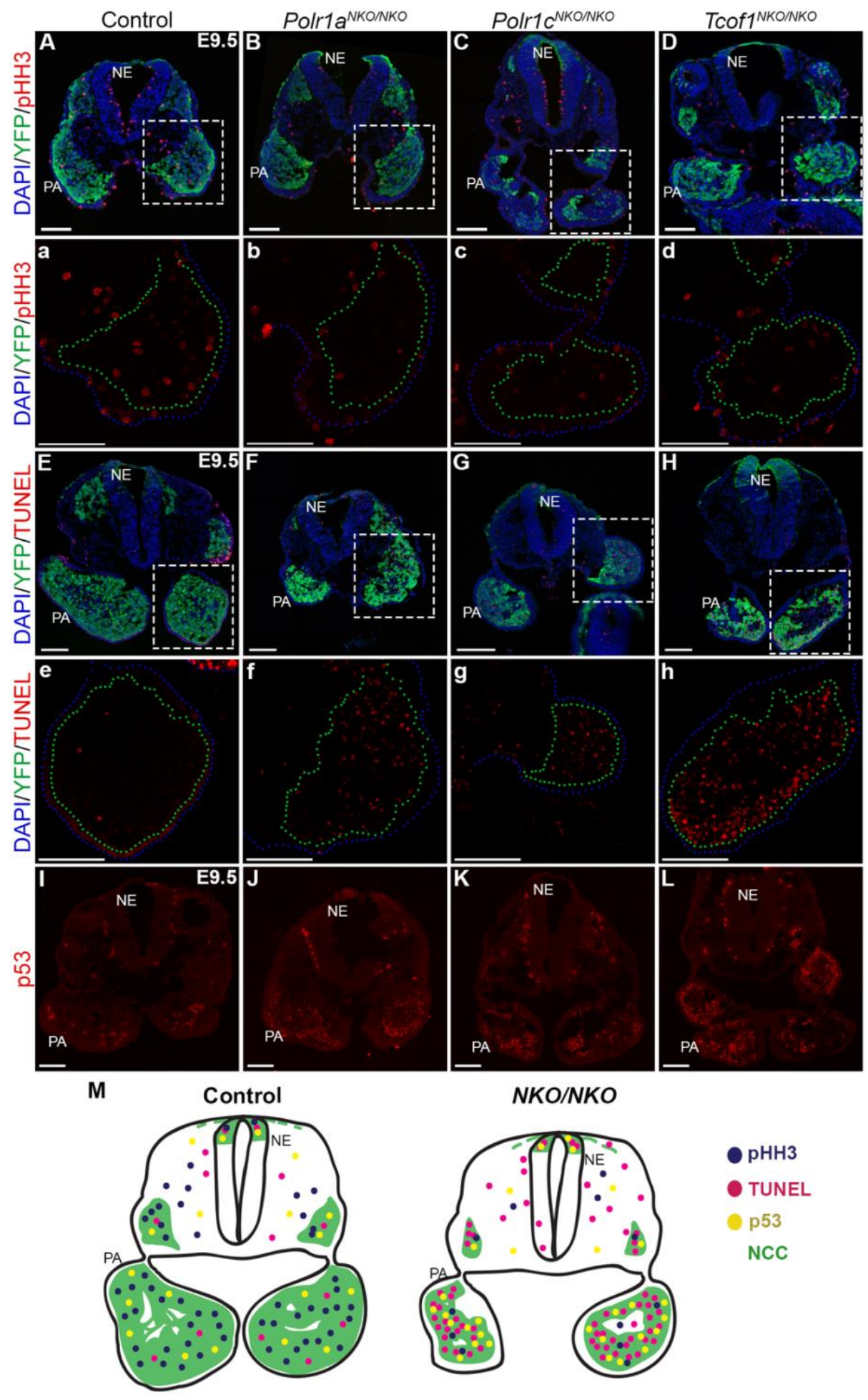


Fig. 5. Reduced proliferation and increased p53-dependent cell death underlies the reduced NCC population in Polr1a ${ }^{N K O / N K O}$, Polr1c $^{\text {NKO/NKO }}$ and Tcof1 $\mathbf{T K O}^{\text {NKKO }}$ mice. (A-D) Proliferation (pHH3, red) is reduced in NCC (YFP+) of Polrla $a^{N K O / N K O}$, Polrl $c^{N K O / N K O}$, and Tcofl $1^{N K O / N K O}$ embryos. (a-d) Higher magnification view of boxed region in A-D. Pharyngeal arches are outlined in green, indicative of the YFP expressing cell boundary and blue, indicative of DAPI labeled cell boundary. (E-H) TUNEL staining shows increased cell death in YFP+ NCC in the pharyngeal arches of Polrla ${ }^{N K O / N K O}, P o l r l c^{N K O / N K O}$, and Tcof1 $1^{\text {NKOINKO }}$ embryos at E10.5. (e-h) Higher magnification of the pharyngeal arches, YFP expressing region outlined in green and DAPI with blue. (I-L) Increased p53 staining in the pharyngeal arches in Polrla $a^{N K O / N K O}$, Polrl ${ }^{N K O / N K O}$, and Tcof1 ${ }^{N K O / N K O}$ embryos suggests p53-dependent cell death. (M) Summary schematic of control and NCC-specific mutant (representative of Polrla ${ }^{\text {NKONNKO }}$, Polrlc ${ }^{\text {NKO/NKO }}$, and $T c o f 1^{N K O / N K O}$ ) sections depicting decreased levels of pHH3 (blue), increased cell death (pink) and p53 (yellow) levels within NCC (green). Abbreviations. NCC, neural crest cells; NE, neuroepithelium; PA, pharyngeal arches. Scale bar $=100 \mu \mathrm{m}$. 

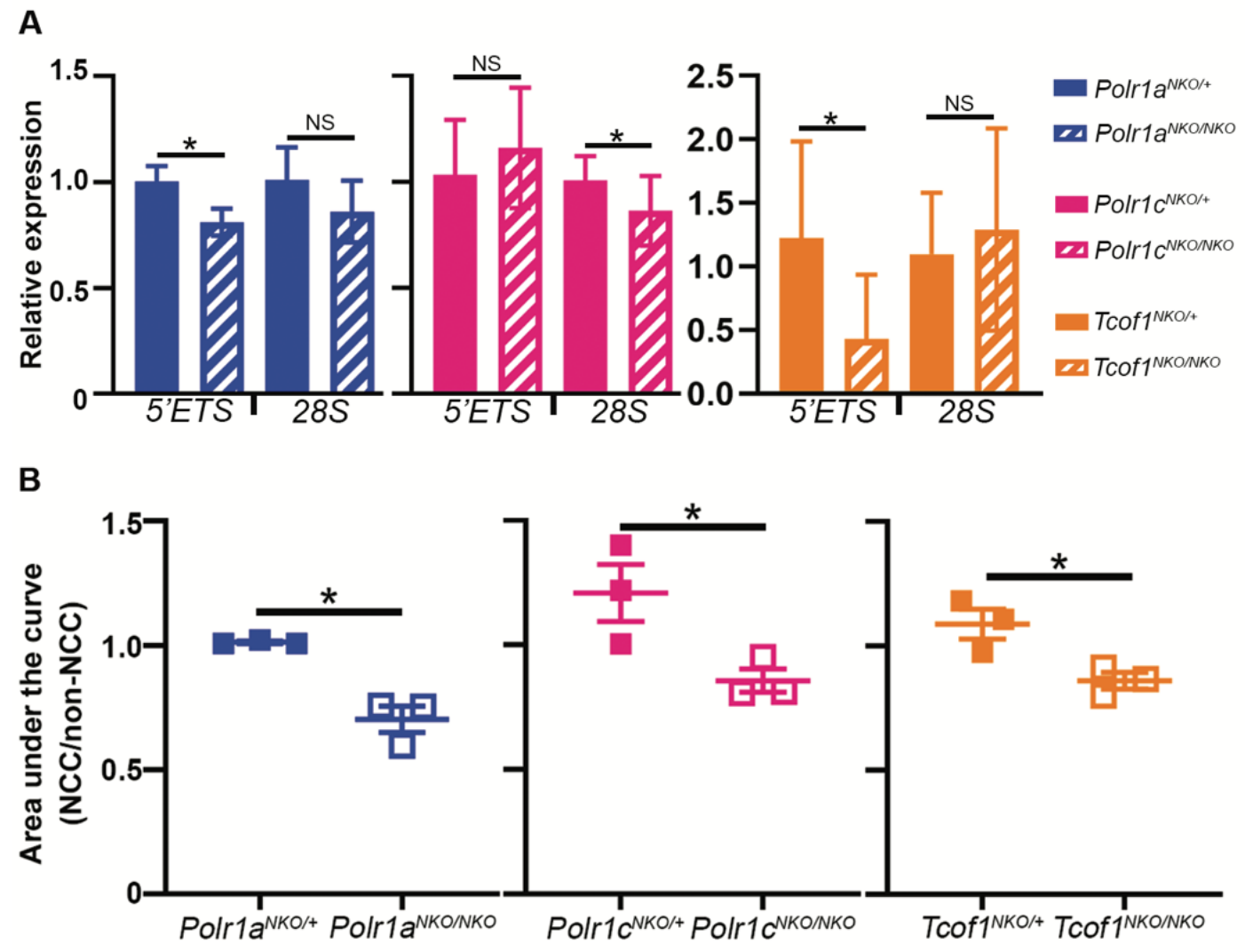

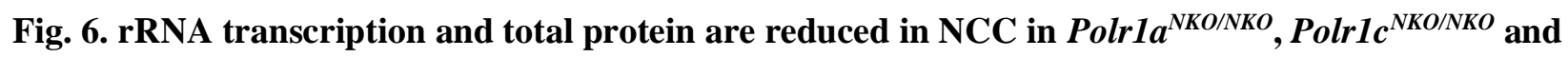
Tcof1 ${ }^{\text {NKO/NKO }}$ mice. (A) qPCR for the 5'ETS region of rRNA is significantly reduced in the sorted NCC of Polrl $a^{\text {NKO/NKO }}$ and Tcofl $1^{\text {NKO/NKO }}$ embryos, while mature $28 \mathrm{~S}$ rRNA transcript is not significantly changed. In Polrl $c^{N K O / N K O}$ embryos, 28S rRNA is reduced while 5'ETS is not significantly affected. (B)

Quantification of silver staining demonstrates the total protein in NCC is significantly reduced compared

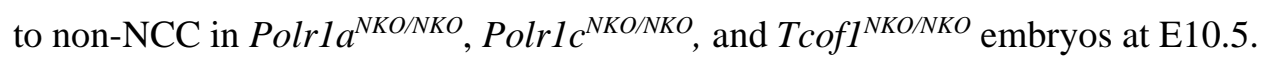




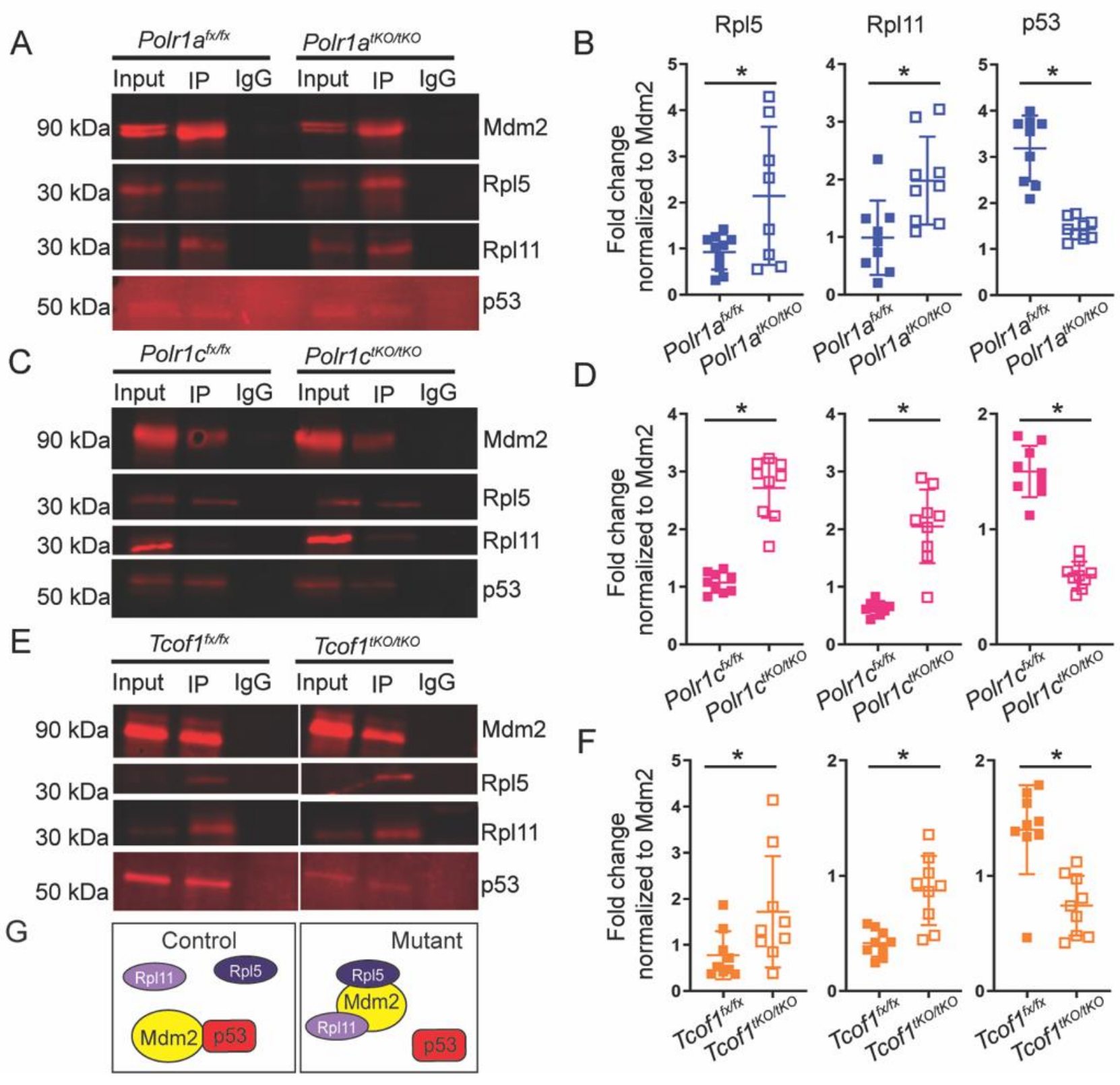

Fig. 7. p53 is activated as a result of higher ribosomal protein binding to Mdm2 in mutant mouse

embryonic fibroblasts. Mouse embryonic fibroblast cells (MEFs) derived from Polrla $a^{f l x f l x}$, Polr $1 a^{t K O / t K O}$

(A-B), Polrlc $c^{f l x f l x}$, Polrl $c^{t K O / t K O}$. (C-D), Tcof $1^{f l x f f l x}$, and Tcof $1^{t K O / t K O}$ (E-F) embryos were treated with 
tamoxifen and used for immunoprecipitation assays. Pull down with Mdm2 and immunoblotting for Rpl5 and Rpl11 revealed increased binding of Mdm2-Rpl5 and Mdm2-Rpl11 in Polrla ${ }^{t K O / K O}$, Polrlc ${ }^{t K O / t K O}$, and $T c o f 1^{t K O / K O}$ MEFs compared to their respective control MEFs. Conversely, p53 binding to Mdm2 is reduced in Polrla ${ }^{t K O / t K O}$, Polrl $c^{t K O / t K O}$, and $T c o f 1^{t K O / K O}$ MEFs compared to controls, consistent with the

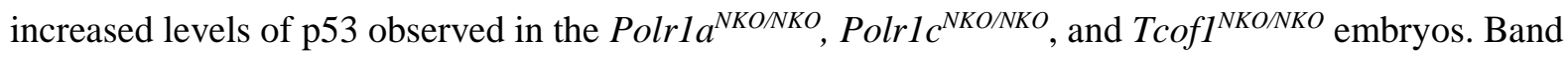
intensities were measured as the ratio between Mdm2 and Rpl5, Rpl11, or p53. (G) Summary schematic showing Mdm2-p53 binding in control and Rpl5, Rp111-Mdm2 binding in mutant resulting in free p53.* indicates $\mathrm{p}<0.05$, Student's t-test. 


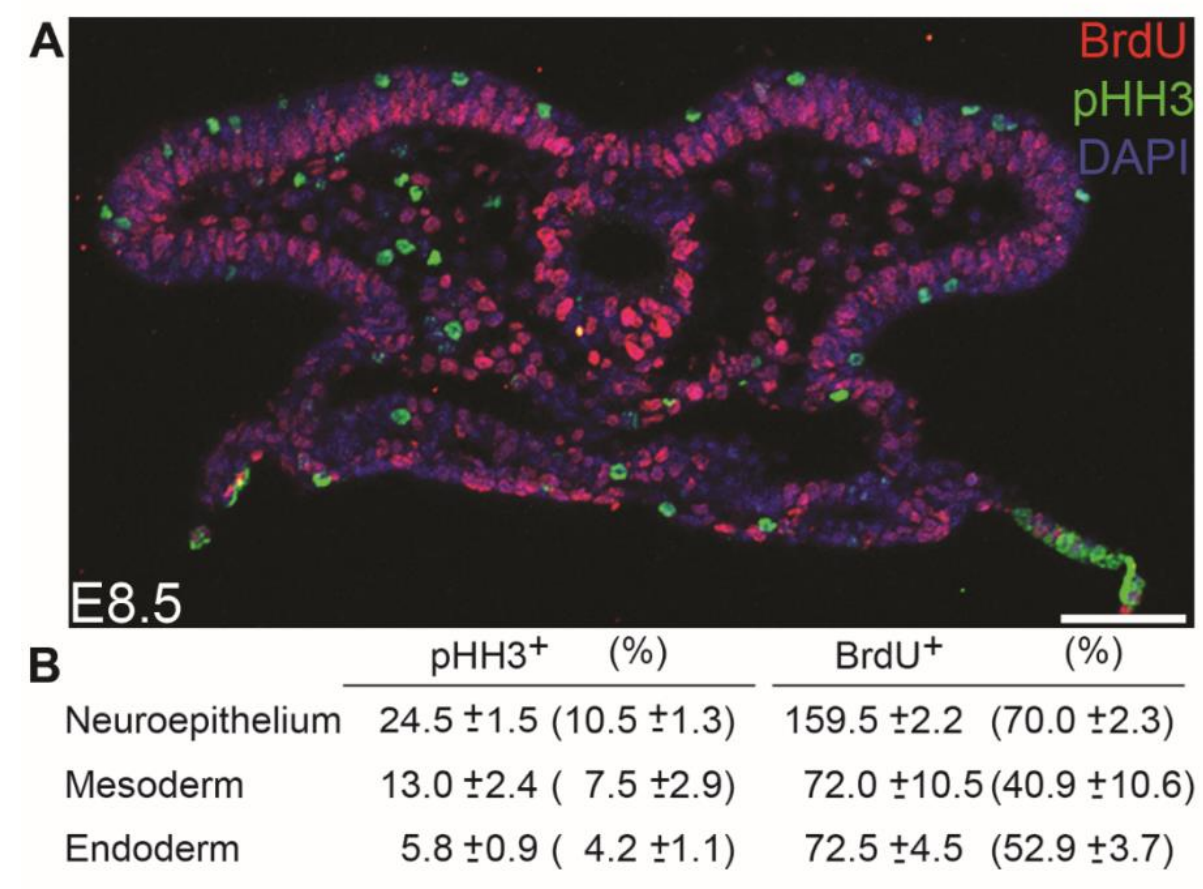

Fig. S1. The neuroepithelium is highly proliferative. (A-B) A higher number of cells in the neuroepithelium, which includes premigratory $\mathrm{NCC}$, are $\mathrm{pHH} 3$ and BrdU positive compared to surrounding mesoderm and endoderm cells, indicating the neuroepithelium is more highly proliferative at E8.5 in wild-type embryos. Scale bar $=80 \mu \mathrm{m}$. 


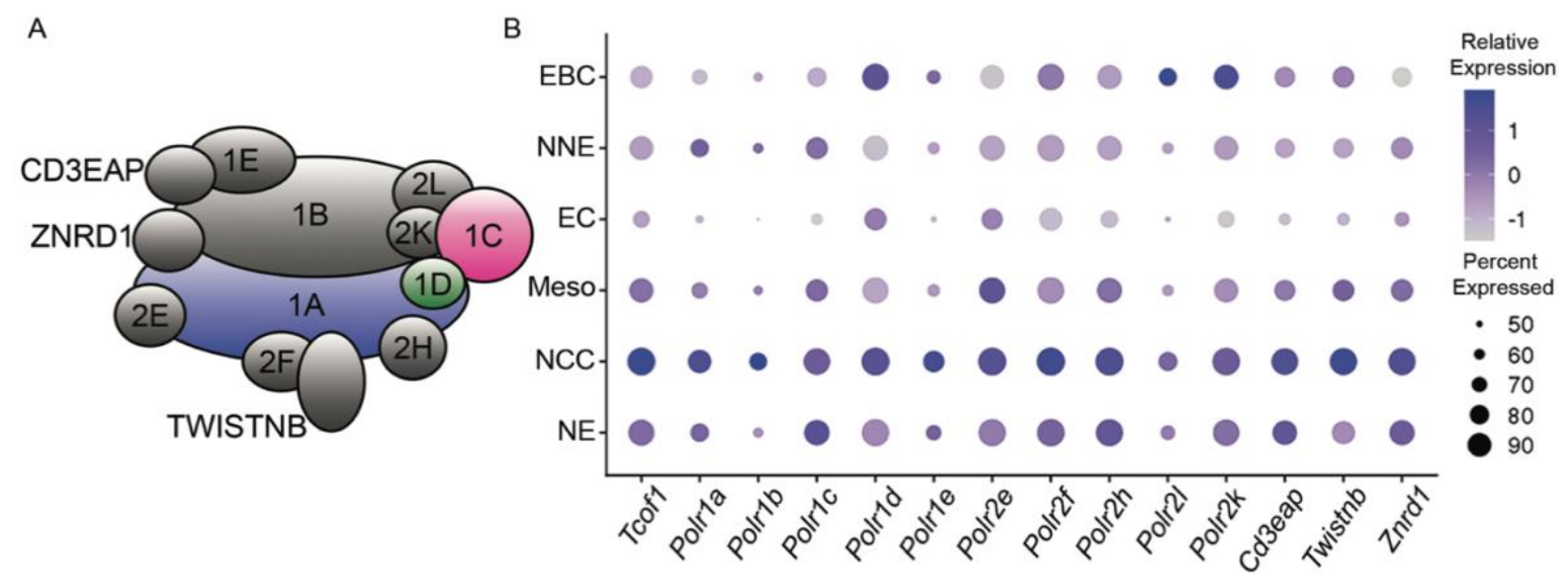

Fig. S2. Pol I subunits are expressed highly in NCC. A) Schematic of RNA Polymerase I

subunits. B) Single cell RNA-seq analysis identifies Tcofl and RNA Polymerase I subunit

transcripts to be highly expressed in neuroepithelium and NCC compared to other tissues in the craniofacial region of E8.5 mouse embryos. The size of the circle represents the percent of cells in a population expressing the transcript of interest, while color intensity represents the relative level of transcripts expressed in a cell population (see Methods). Abbreviations: EBC, embryonic blood cells; EC, endothelial cells; Meso, mesoderm; NCC, neural crest cells; NE, neuroepithelium; NNE, non-neural ectoderm. 


\section{A}
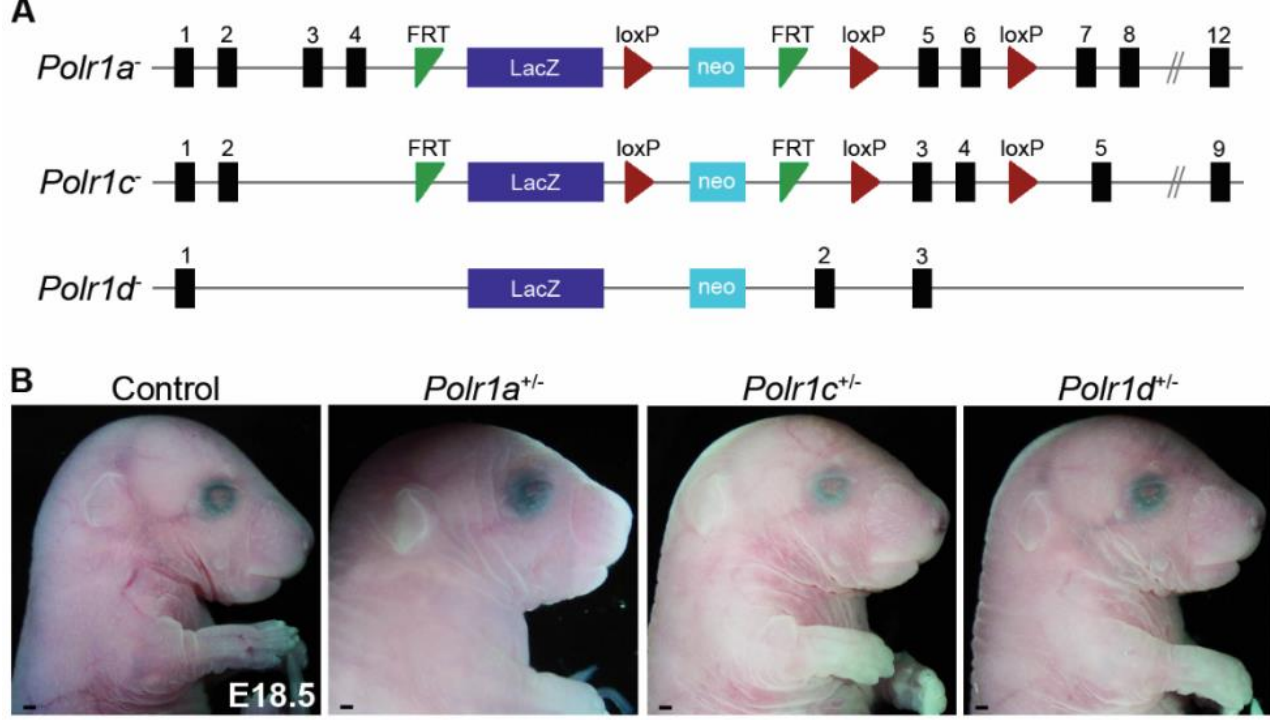

C Control Polr1a ${ }^{-1-}$

Polr1c ${ }^{-1-}$

Polr1d ${ }^{\prime-}$
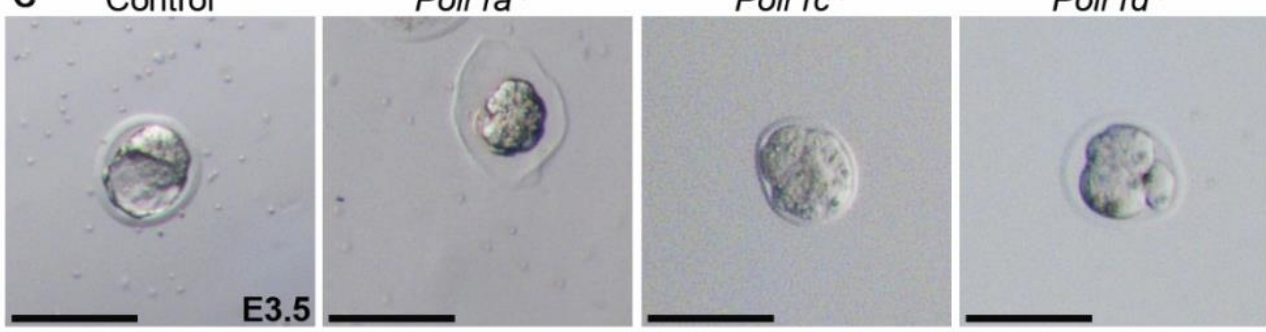

Fig. S3. Generation of Polr1a, Polr1c and Polr1d mutant mice. (A) A LacZ-neo cassette containing loxP sites flanking critical exons of Polrla and Polrlc was used to generate Polrla ${ }^{+/-}$ and Polrlc $c^{+/}$alleles. The Polrld $d^{+/}$allele was generated by disrupting the Polrld gene with a LacZ-neo insert. (B) Heterozygous mutants of Polrla, Polrlc and Polrld are indistinguishable from wild-type controls indicating a single copy of Polrla, Polrlc and Polrld is sufficient for embryonic development. Scale bar $=500 \mu \mathrm{m}(\mathrm{C})$ Null mutants of Polrla, Polrlc and Polrld survive until the uncompacted morula stage at E3.0 and are fragmented by E3.5 while wildtype embryos proceed to the blastocyst stage indicating Polrla, Polrlc and Polrld are required for pre-implantation embryo survival. Scale bar $=100 \mu \mathrm{m}$. 


\section{TREACLE avg Control avg}

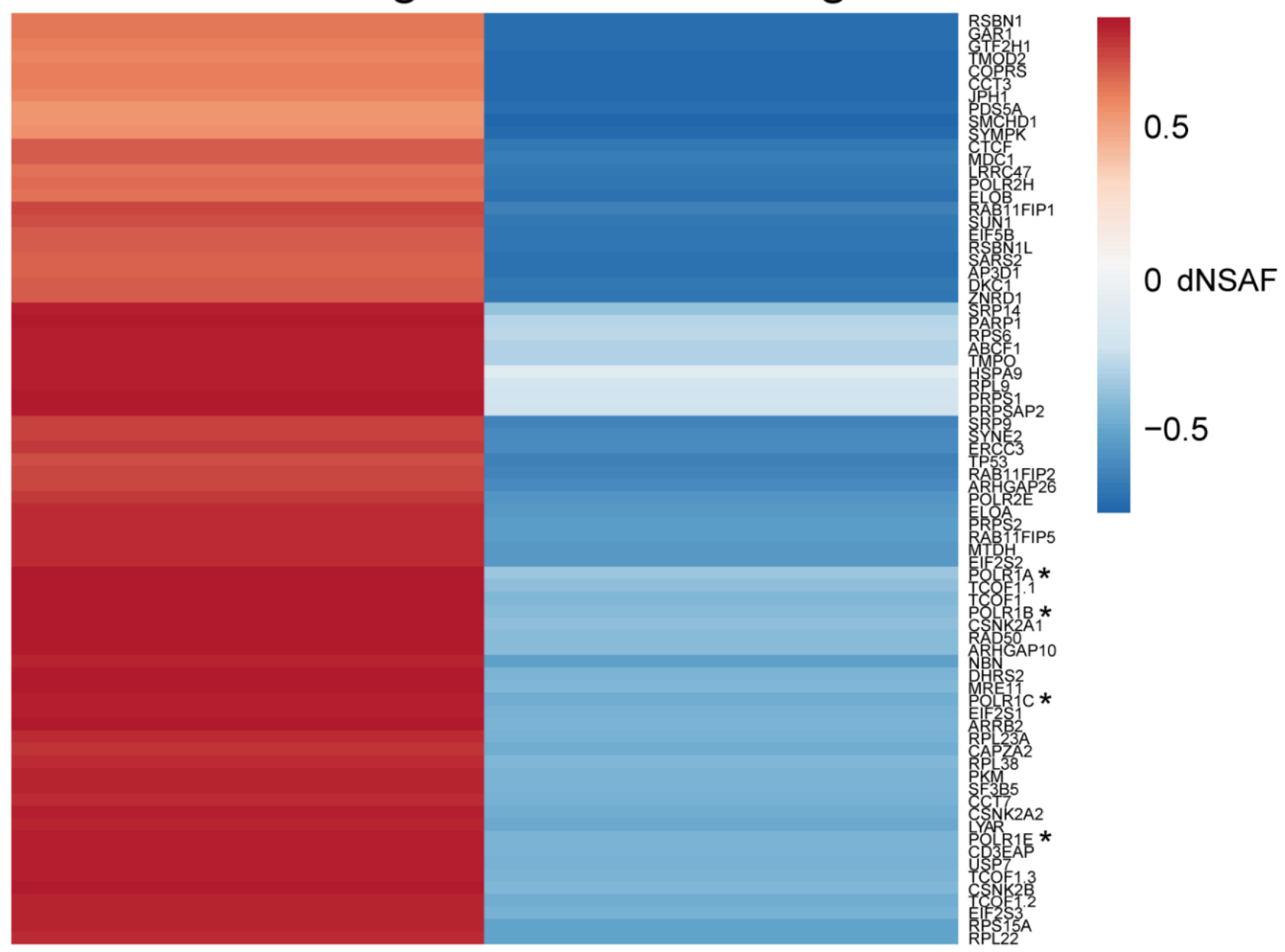

Fig. S4 Proteins identified by multidimensional protein identification technology with

TREACLE as the bait. Heat map showing the spectral abundance of proteins pulled down with FLAG-tagged TREACLE in both antibody and IgG (control) immunoprecipitation conditions, expressed as distributed normalized spectral abundance factor (dNSAF). This demonstrates the specificity of TREACLE binding to its target proteins. * Pol I protein subunits. 

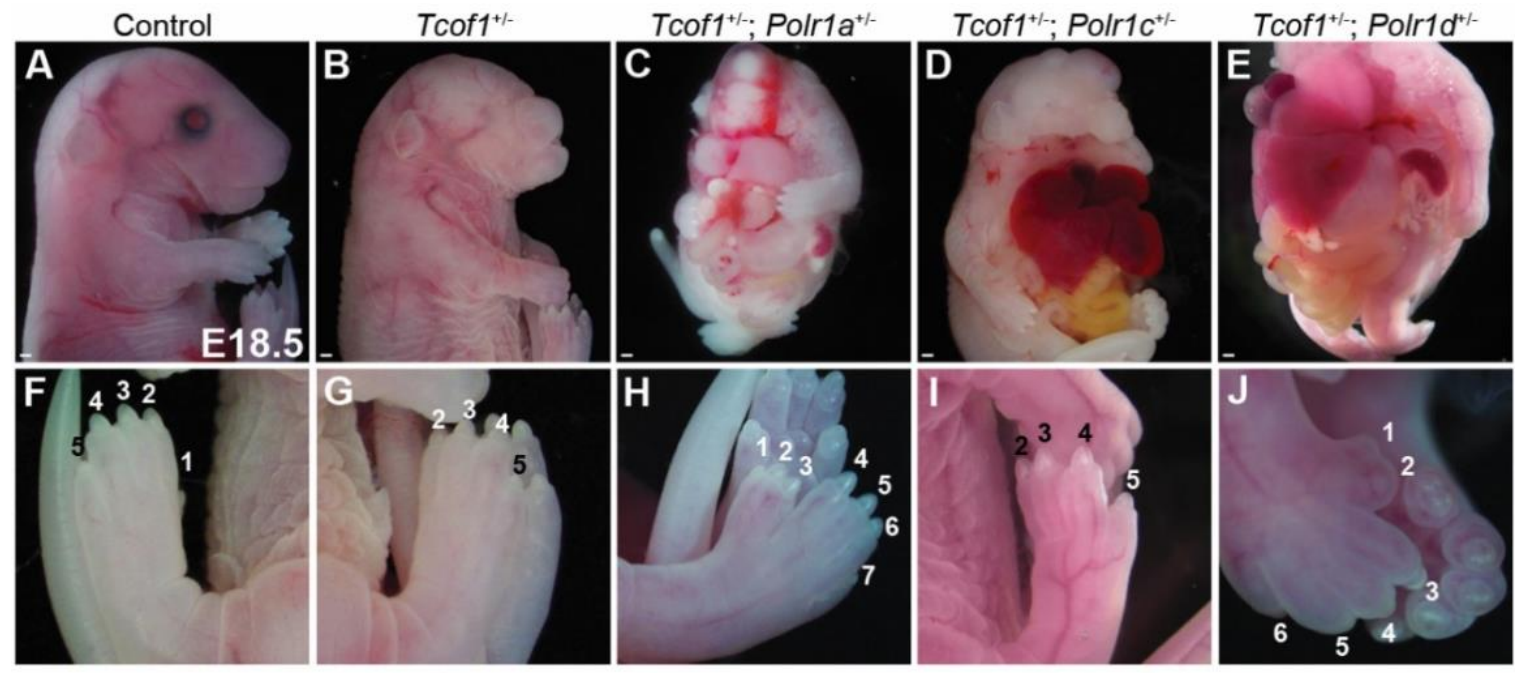

Fig. S5. Double mutants of Tcof1 with Polr1a, Polr1c, and Polr1d exhibit thoracoschisis and

digit defects. (A-E) Compared to controls and $T c o f 1^{+/}$embryos, $T c o f 1^{+/} ;$Polrla $^{+/}, T_{c o f} 1^{+/}$;

Polrlc $^{+/}$and $\mathrm{Tcofl}^{+/}$; Polr $1 d^{+/}$double mutants exhibit variably penetrant thoracoschisis as

evidenced by herniation of lung, liver and gut at variable penetrance. Scale bar $=500 \mu \mathrm{m}$. (F-J)

Tcofl $^{+/} ;$Polrla $^{+/-}$, Tcof1 $1^{+/} ;$Polrlc $^{+/-}$and Tcofl $^{+/-} ;$Polrld $^{+/-}$double mutants exhibit digit

defects including duplication of digit $1(\mathrm{H}, \mathrm{J})$ and shorter, broader digits (I). 


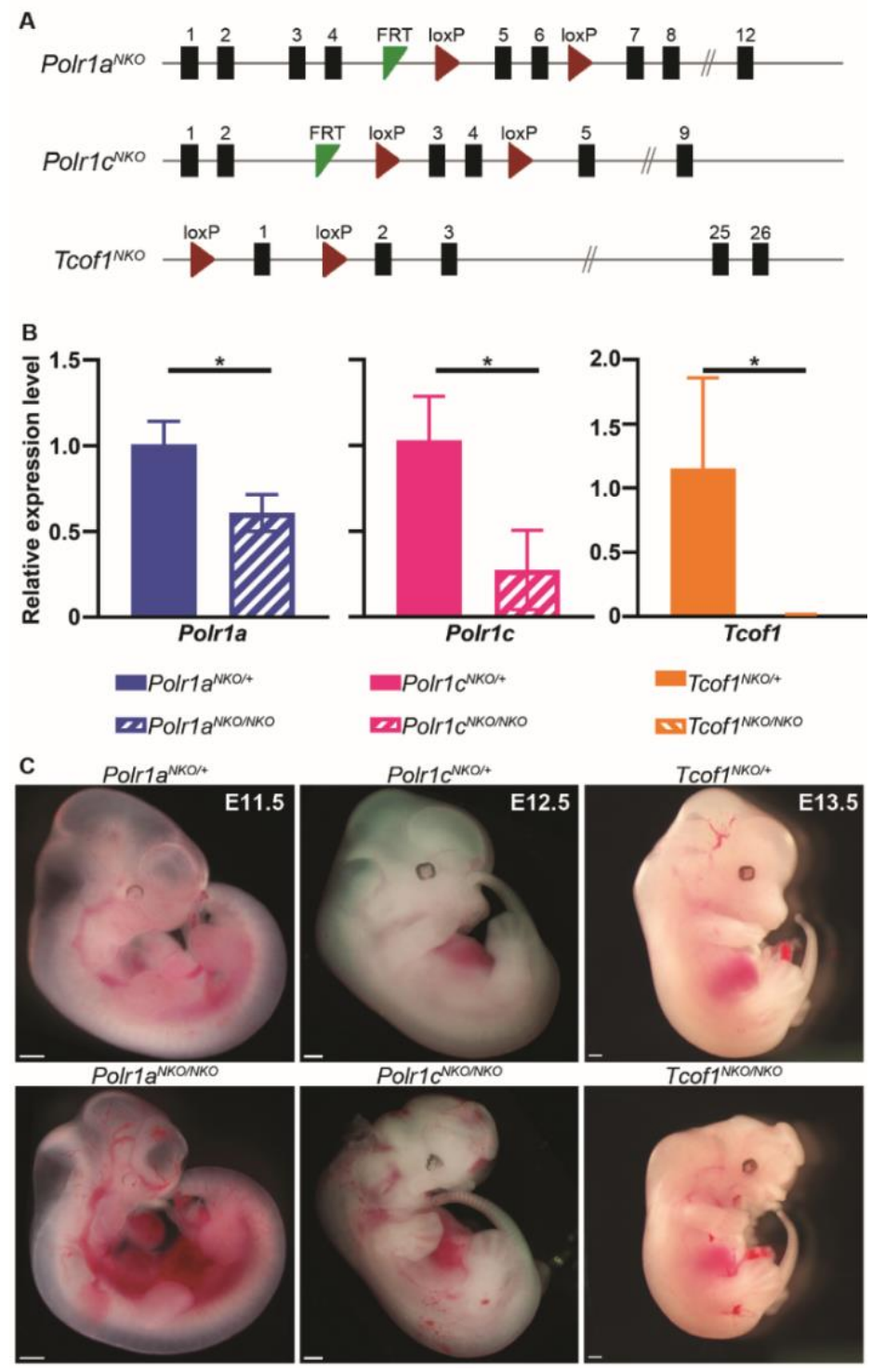

Fig. S6. NCC-specific mutants of Polr1a, Polr1c and Tcof1 exhibit mid-gestation lethality.

(A) NCC-specific knockouts of Polrla (Polr1a $\left.{ }^{N K O}\right)$, Polrlc $\left({\left.\text { Polr } 1 c^{N K O}\right) \text { and Tcofl (Tcofl }}^{\text {NKO }}\right)$ were generated by flanking critical exons with loxP sites and breeding the floxed allelic mice with Wnt1-Cre transgenic mice. (B) qPCR reveals reduced expression of Polrla, Polrlc, and Tcofl transcripts in sorted NCC from Polrla ${ }^{N K O / N K O}$, Polrl $c^{N K O / N K O}$, and Tcof1 ${ }^{\text {NKO/NKO }}$ embryos, respectively, compared to their control littermates at E9.5. *indicates $\mathrm{p}<0.05$, Student's t-test. (C) While a single copy of Polrla, Polrlc and Tcofl in NCC is sufficient for embryonic 
bioRxiv preprint doi: https://doi.org/10.1101/2021.09.22.461379; this version posted September 22, 2021. The copyright holder for this preprint (which was not certified by peer review) is the author/funder, who has granted bioRxiv a license to display the preprint in perpetuity. It is made available under aCC-BY-NC-ND 4.0 International license.

development, knocking out both copies of Polrla, Polrlc and Tcofl from NCC results in midgestation lethality. Scale bar $=500 \mu \mathrm{m}$. 


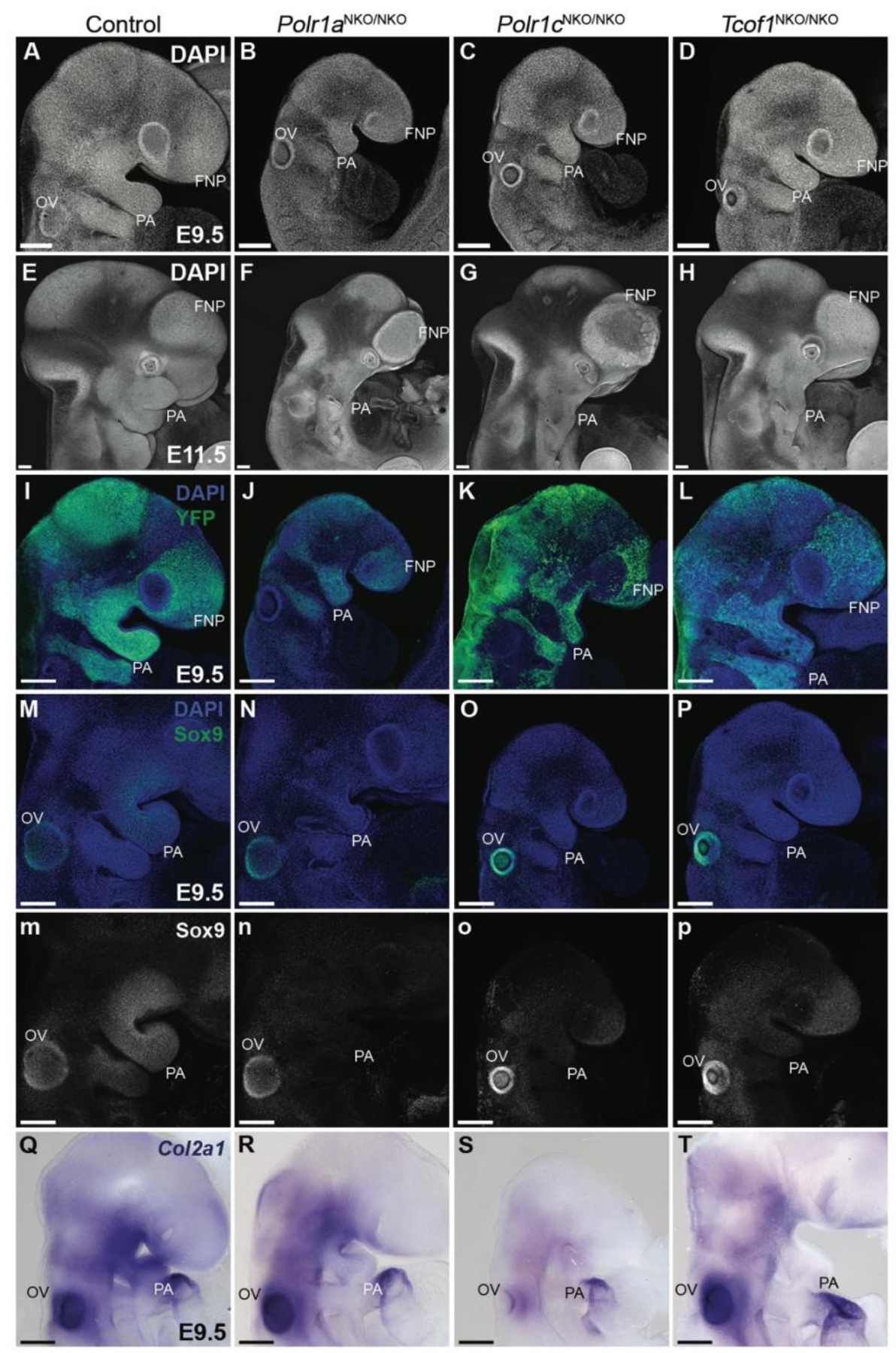

Figure S7. Craniofacial defects in Polr1a ${ }^{N K O / N K O}$, Polr1 $c^{N K O / N K O}$ and Tcof1 ${ }^{N K O / N K O}$ mice. (AH) DAPI staining of control, Polrla $a^{N K O / N K O}$, Polrl $c^{N K O / N K O}$ and Tcof1 ${ }^{N K O / N K O}$ embryos at E9.5 and E11.5 shows hypoplastic pharyngeal arches and frontonasal prominences in Polrla ${ }^{N K O / N K O}$, Polrl ${ }^{N K O / N K O}$ and Tcof1 $1^{\text {NKO/NKO }}$ embryos. (I-L) Analysis of the NCC lineage with RosaeYFP 
indicates that fewer NCC migrate to the pharyngeal arches in Polrla ${ }^{N K O / N K O}$, Polrl $c^{N K O / N K O}$ and Tcof1 ${ }^{N K O / N K O}$ at E9.5. (M-P) Immunostaining for Sox9, a marker indicative of NCC migration and differentiation to chondrocytes (green in M-P and gray in m-p). Sox9 is significantly reduced in the pharyngeal arches of Polrla $a^{N K O / N K O}$, Polrl $c^{N K O / N K O}$ and $T c o f 1^{N K O / N K O}$ embryos, indicating a reduction in the number of NCC precursors necessary for craniofacial cartilage development. (QT) Consistent with this, Type II collagen Col2al transcription is drastically reduced in the pharyngeal arches of Polrla $a^{N K O / N K O}$, Polrl $c^{N K O / N K O}$ and Tcof1 $1^{N K O / N K O}$ embryos at E9.5. Abbreviations. FNP, Frontonasal prominence; NE, neuroepithelium; OV, Otic vesicle. PA, pharyngeal arches; Scale bar $=200 \mu \mathrm{m}$. 

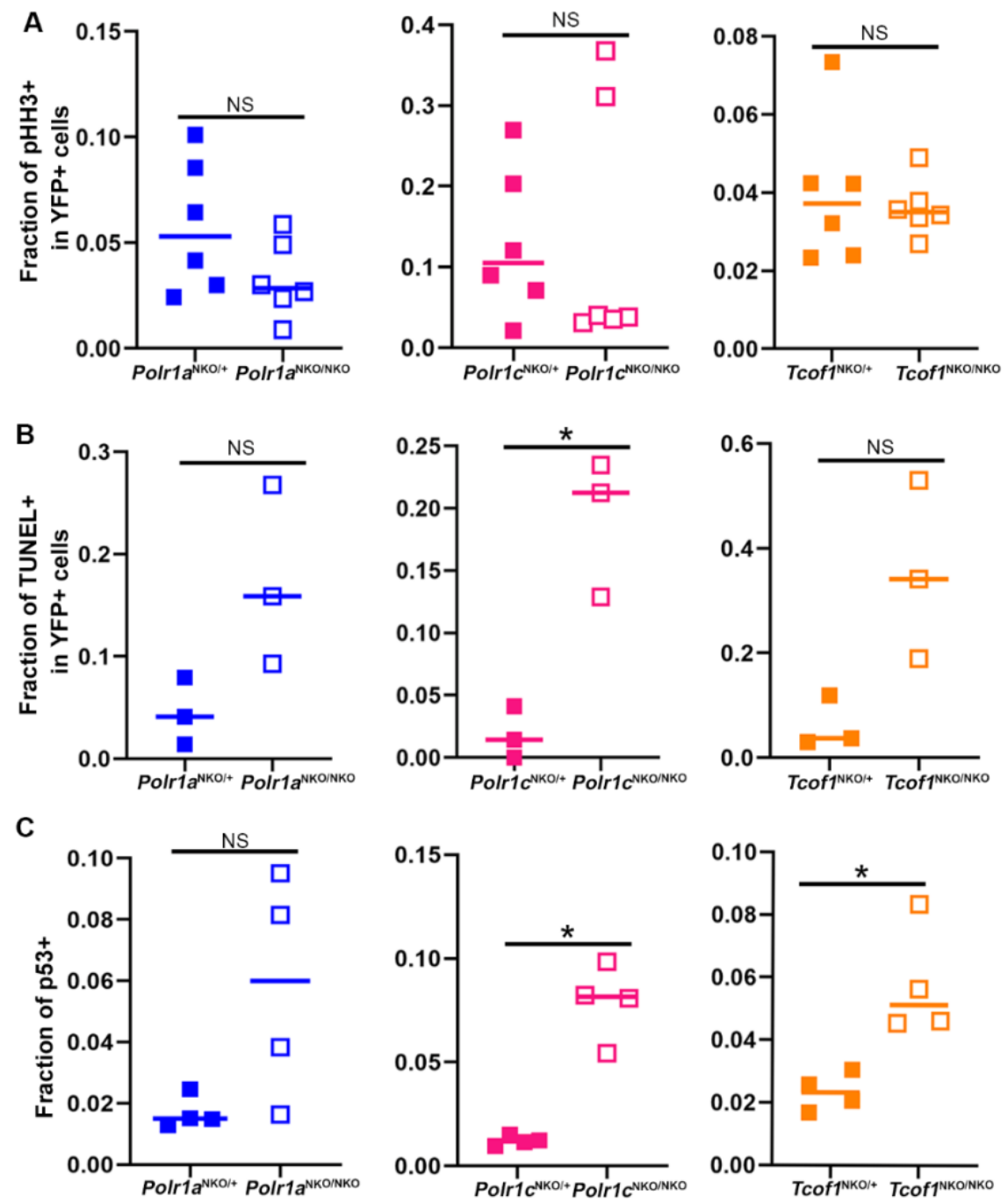

Figure S8. Quantification of pHH3, TUNEL, and p53 in NCC of Polr1a ${ }^{N K O / N K O}$,

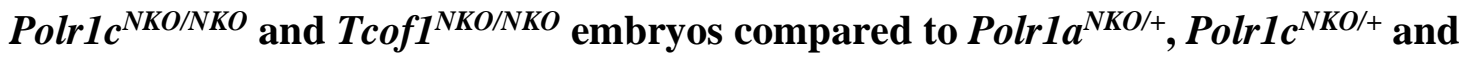
Tcof1 $^{\text {NKO/+ }}$ controls. (A) Quantification of $\mathrm{pHH} 3+$; YFP+ cells demonstrates that $\mathrm{pHH} 3$ staining in the NCC at E9.5 tends to be less in $N K O / N K O$ mutants relative to littermate controls, however this difference was not statistically significant. (B) Quantification of TUNEL+YFP+ cells reveals increased cell death in NKO/NKO mutants. This trend was statistically significant in Polrlc $c^{N K O / N K O}$ embryos. (C) Similarly, quantification of p53+ cells revealed increased levels of 
bioRxiv preprint doi: https://doi.org/10.1101/2021.09.22.461379: this version posted September 22. 2021. The copvriaht holder for this preprint (which was not certified by peer review) is the author/funder, who has granted bioRxiv a license to display the preprint in perpetuity. It is made available under aCC-BY-NC-ND 4.0 International license.

p53 in NKO/NKO mutants. This trend was statistically significant in Polr $1 c^{N K O / N K O}$ and Tcof1 ${ }^{\text {NKO/NKO }}$ embryos relative to their littermate controls. * indicates $\mathrm{p}<0.05$, Student's t-test. 


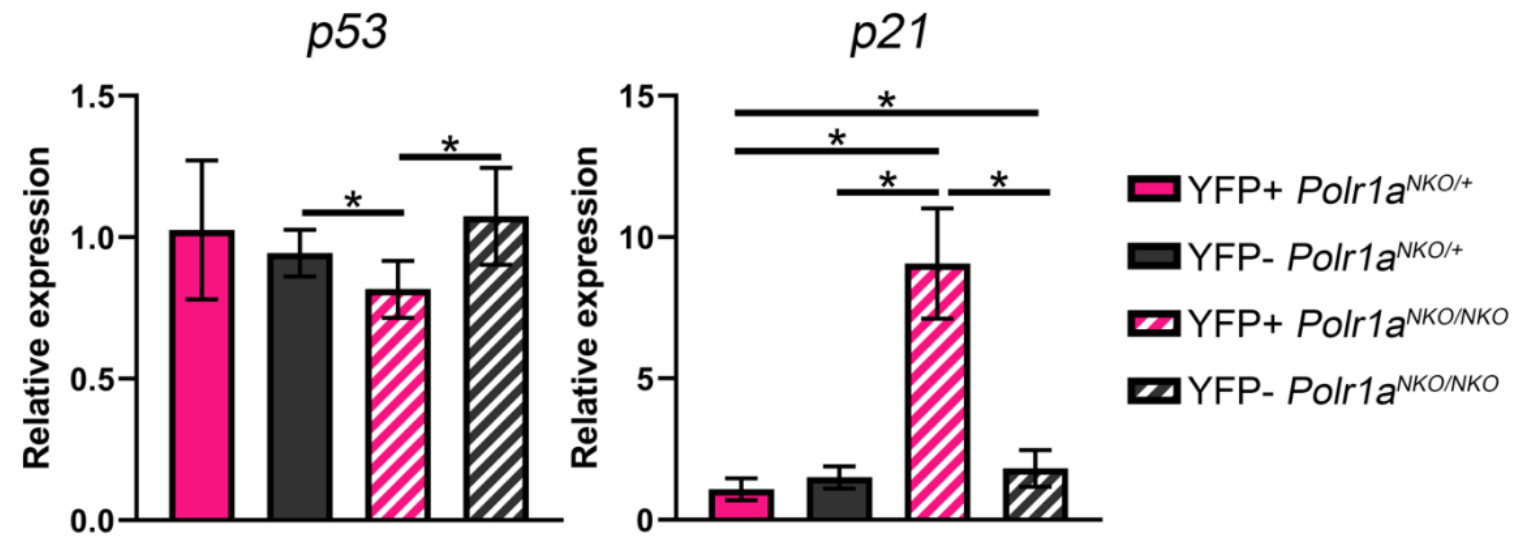

Figure S9. Quantification of p53 and p21 transcript in NCC and non-NCC of Polr1a ${ }^{N K O / N K O}$ embryos compared to Polr1a ${ }^{\mathrm{NKO} /+}$ controls. qPCR for $p 53$ demonstrates that $p 53$ levels are not significantly changed in NCC versus non-NCC in control embryos (YFP+Polrla ${ }^{N K O /+}$ vs. YFPPolrl $a^{N K O /+}$ ) while $p 53$ transcript levels are significantly downregulated in NCC versus nonNCC in mutant embryos (YFP+Polrl $a^{N K O / N K O}$ vs. YFP- Polrl $\left.a^{N K O / N K O}\right)$ and versus non-NCC in controls (YFP+ Polrla $a^{N K O / N K O}$ vs. YFP- Polrl $\left.a^{N K O /+}\right)$. However, p53 levels in the NCC population between $\mathrm{YFP}+P o l r l a^{N K O / N K O}$ mutants and $Y F P+P o l r l a^{N K O /+}$ controls was not significantly changed. qPCR for $p 21$ demonstrates that $p 21$ is significantly upregulated in YFP+ Polrla $a^{N K O / N K O}$ mutants compared to all other cell populations examined. *indicates $\mathrm{p}<0.05$, Welch's ANOVA, Dunnett's T3 multiple comparisons test. 


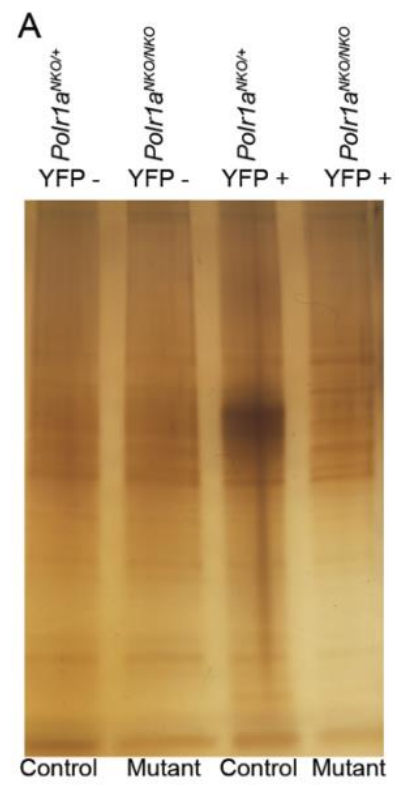

B
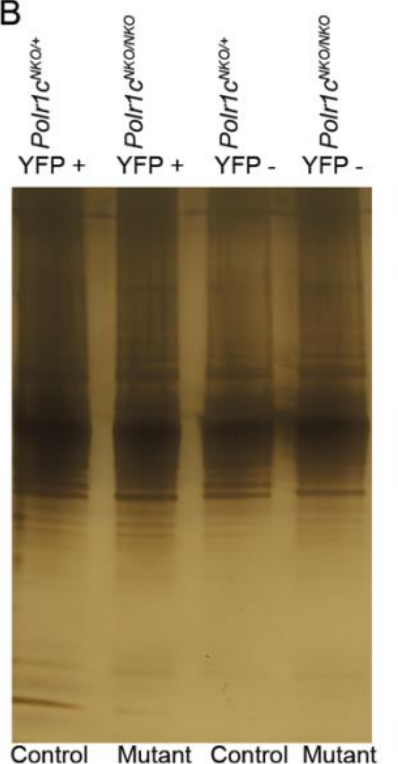

C
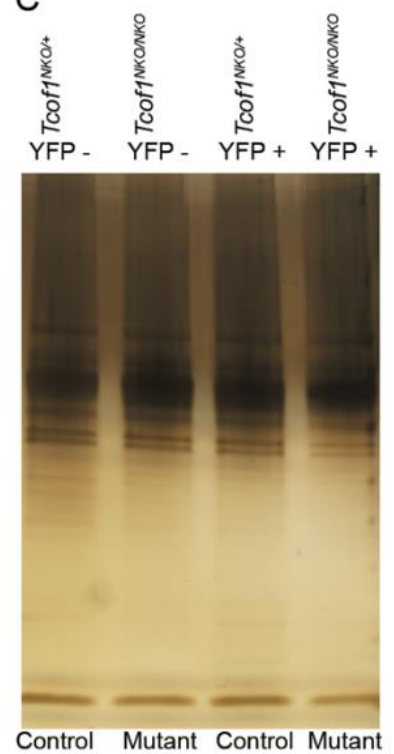

Figure S10. Total protein is significantly reduced in the NCC of Polr1a ${ }^{N K O / N K O}$,

Polr1c ${ }^{N K O / N K O}$ and Tcof1 ${ }^{N K O / N K O}$ mice. (A-C) Silver staining reveals that total protein levels in NCC (YFP+) is slightly higher compared to non-NCC (YFP-) in E10.5 control embryos as observed by the number of bands and intensity of bands in silver-stained gels. However, protein levels in NCC (YFP+) are comparable to non-NCC (YFP-) in mutant Polrla ${ }^{N K O / N K O}$, Polrl ${ }^{N K O / N K O}$ and Tcof1 $1^{N K O / N K O}$ embryos. Compared to control NCC (YFP+), protein expression

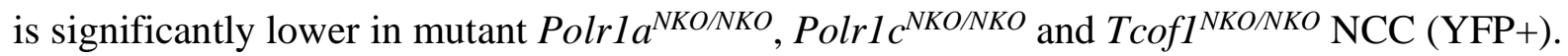




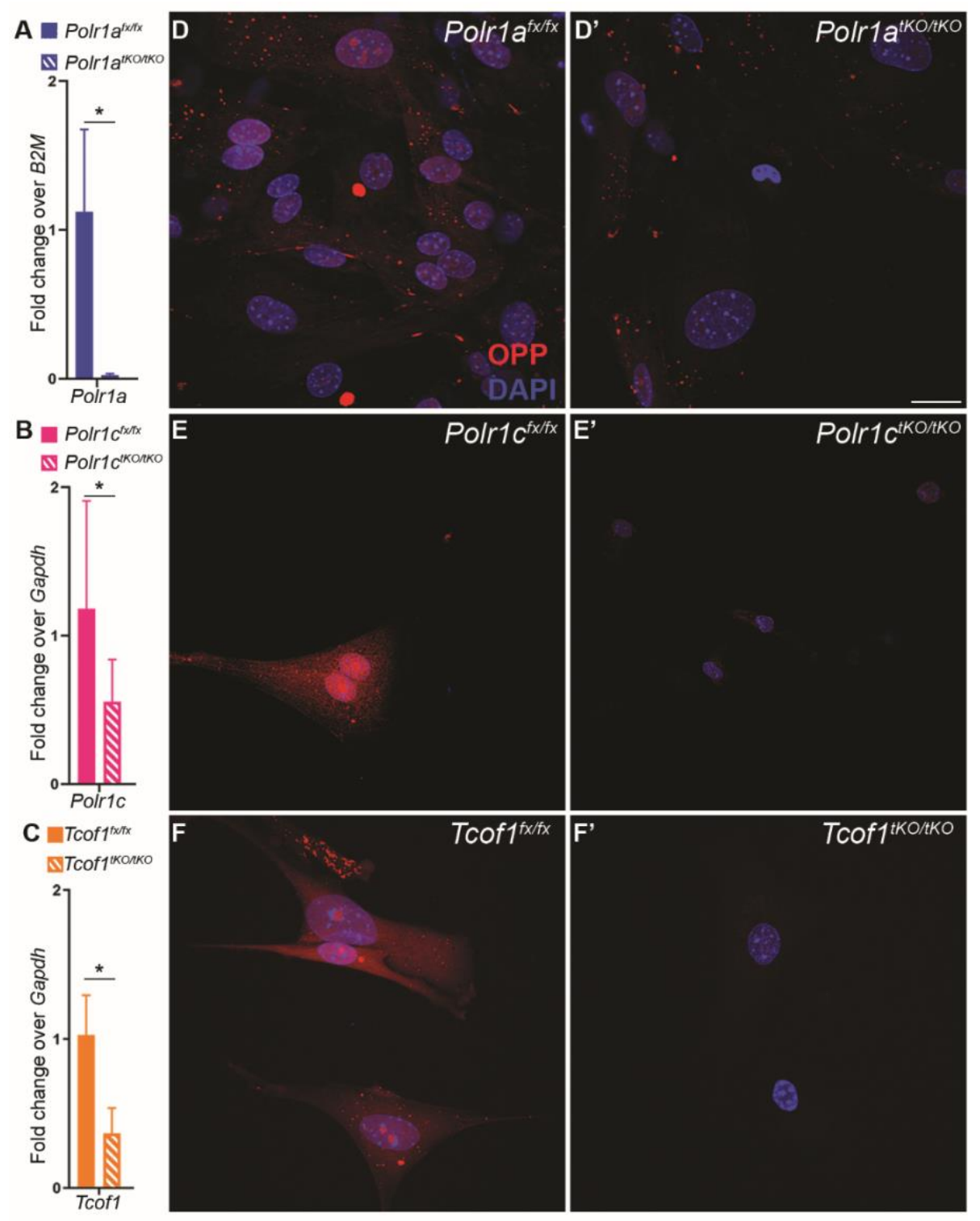

Figure S11. Polr1a ${ }^{t K O / t K O}$, Polr1 $c^{t K O / t K O}$ and Tcof $1^{t K O / t K O}$ mouse embryonic fibroblast cells

have defects in protein synthesis. (A-C) Tamoxifen-treated MEFs generated from

Polrla ${ }^{t K O / t K O}$, Polrl $c^{t K O / t K O}$ and Tcofl ${ }^{t K O / t K O}$ mutant embryos have reduced expression of Polrla,

Polrlc and Tcofl transcripts, respectively. * indicates $\mathrm{p}<0.05$, Student's t-test. (D-F) New

protein synthesis is significantly reduced in Polrla $a^{t K O / t K O}, P o l r l c^{t K O / t K O}$ and $T \operatorname{cof} 1^{t K O / t K O}$ as

observed by OPP staining. Scale bar $=140 \mu \mathrm{m}$. 

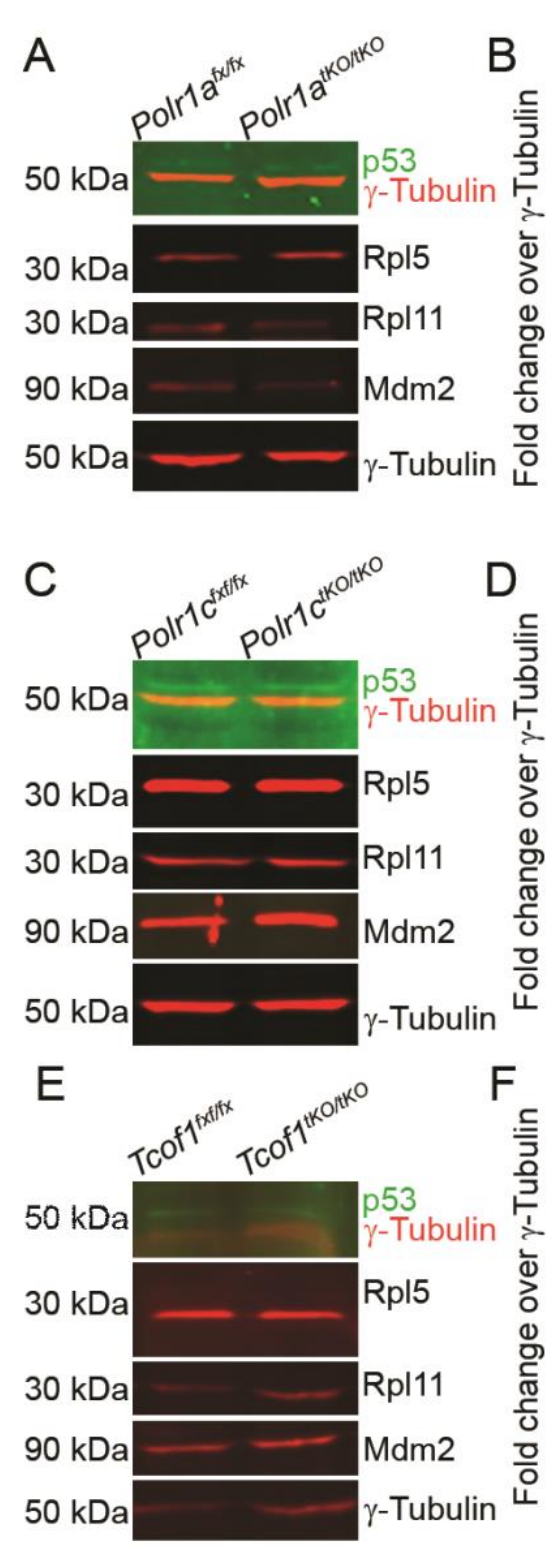

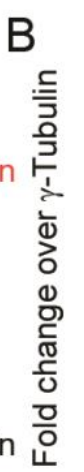

p53
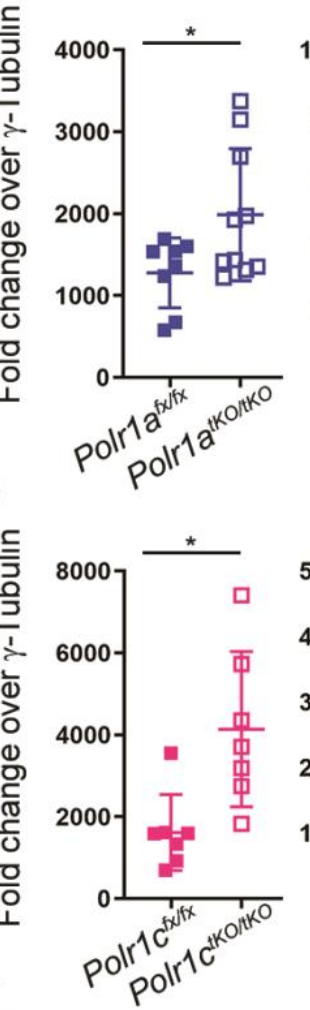

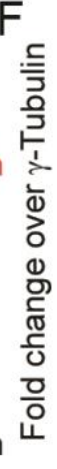

Rpl5
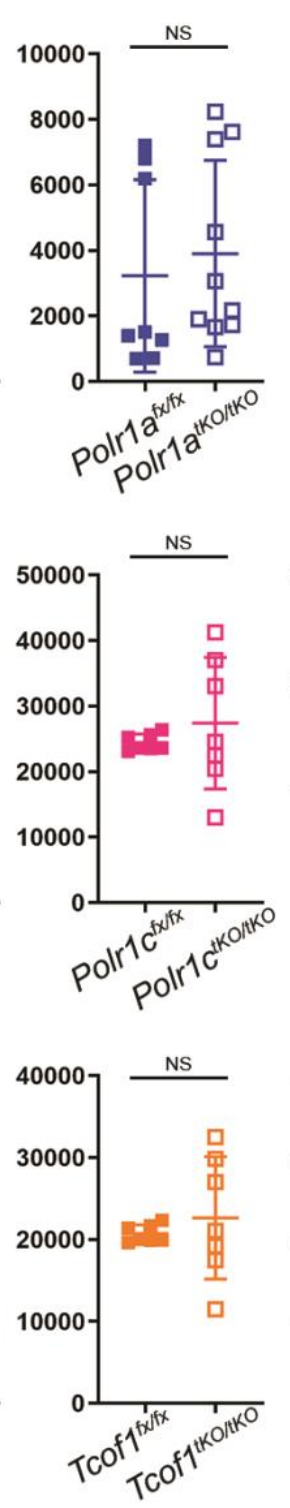

Rpl11
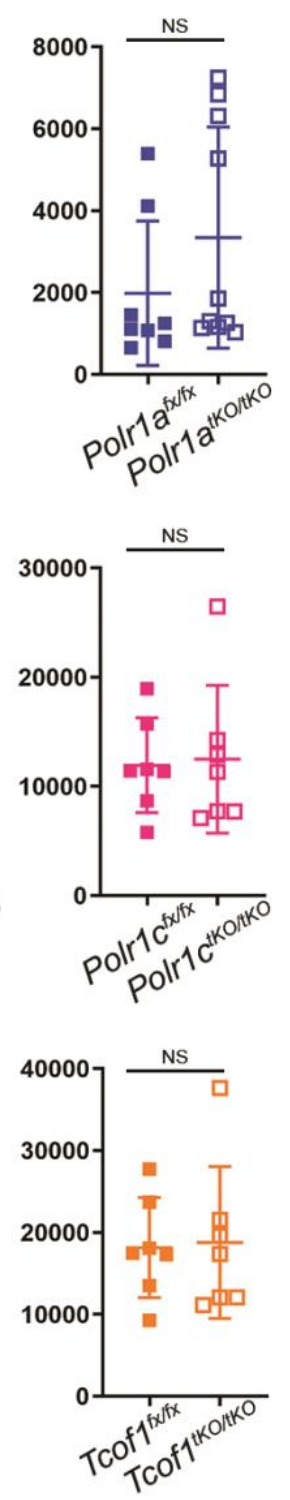

Mdm2
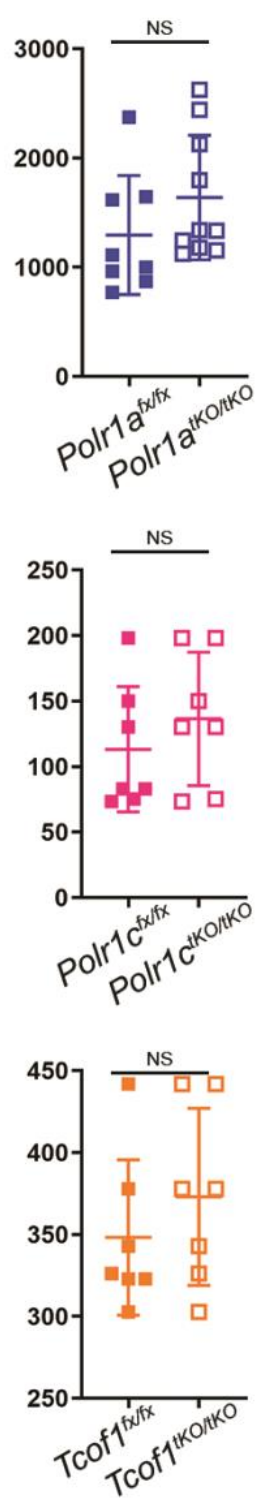

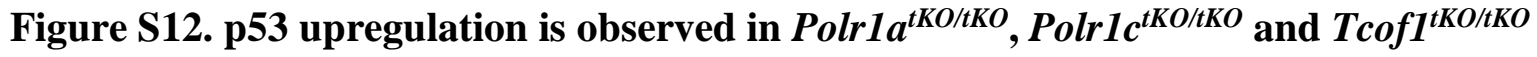

mouse embryonic fibroblast cells. (A-F) Polr $1 a^{t K O / t K O}, P o l r 1 c^{t K O / t K O}$ and Tcofl ${ }^{t K O / t K O} \mathrm{MEFs}$

have increased p53 expression/accumulation. In contrast, Rpl5, Rpl11 and Mdm2 levels are not significantly changed between controls and Polrla $a^{t K O / t K O}$, Polr $1 c^{t K O / t K O}$ and Tcof1 ${ }^{t K O / t K O}$ MEFs. $\mathrm{\gamma}$-Tubulin was used as a housekeeping gene and fold change was calculated as a ratio of band intensities. * indicates $\mathrm{p}<0.05$, Student's t-test. Abbreviations: NS, not significant. 


\section{NE and NCC $\uparrow$ rRNA $\uparrow$ Protein synthesis}

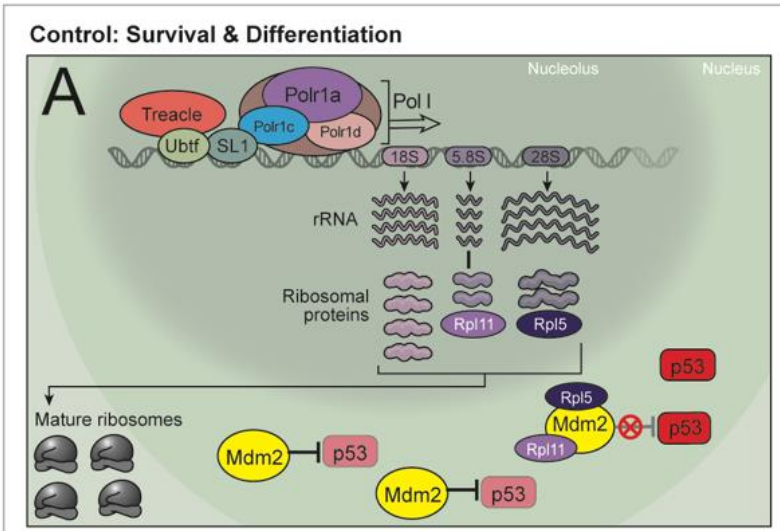

Mutant: Apoptosis

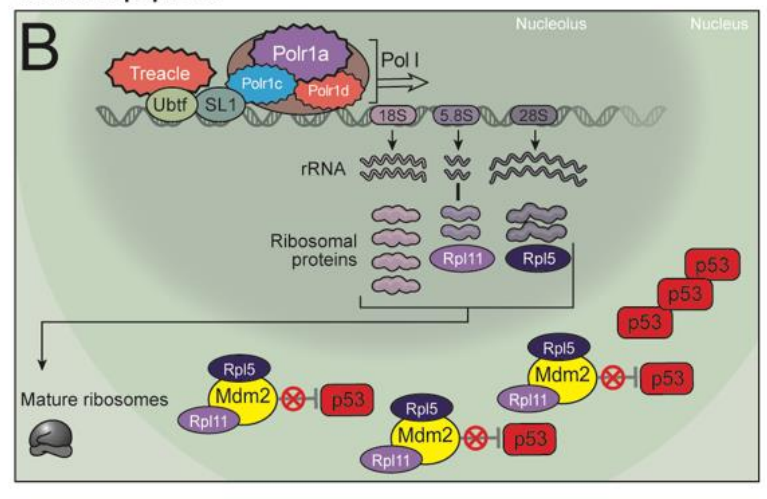

Non-NE and Non-NCC Control: Survival \& Differentiation

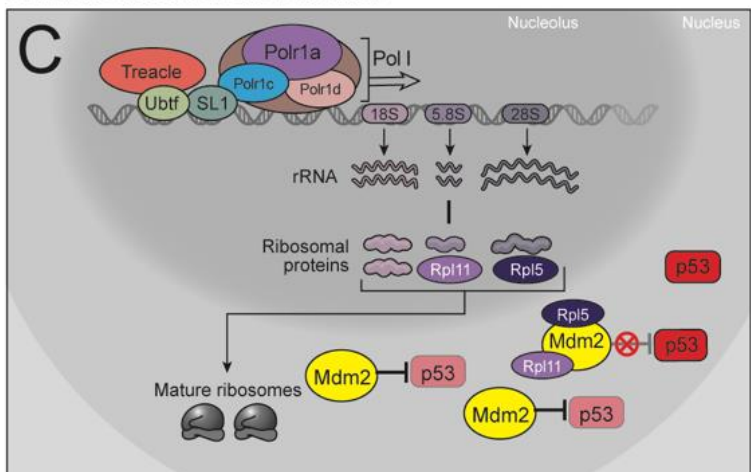

Mutant: Survival \& Differentiation D

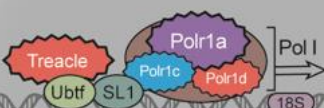

Q.1 (Ubtt) SL1) (185)

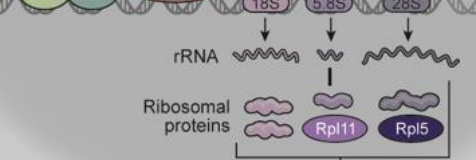

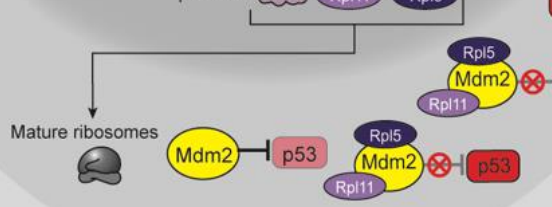

Figure S13. NCC are more sensitive to disruptions in rRNA transcription, which leads to increased susceptibility to p53-dependent cell death. (A) rRNA and ribosomal proteins are maintained in balanced quantities for proper ribosome assembly. The neuroepithelium (NE) and NCC are highly proliferative and have elevated levels of rDNA transcription relative to surrounding tissues, and thus high levels of ribosomal proteins. During normal cell growth and proliferation, Mdm2 protein binds to, and ubiquitinates p53, targeting it for degradation. This typically keeps p53 at low levels and maintains cell survival. (B) Increased levels of rDNA transcription make NE and NCC highly susceptible to disruptions in Pol I mediated transcription. Disruption of rRNA synthesis due to deletion in Pol I subunits Polr1a, Polr1c, Polr1d, or associated factor Treacle, results in increased free ribosomal proteins and thus binding of Rpl5 
and Rpl11 to Mdm2. This inhibits Mdm2 binding and degradation of p53 resulting in p53 protein accumulation. Increased p53 results in NCC apoptosis and craniofacial malformations. (C) Cells with lower proliferative capacity than NE and NCC, have lower rDNA transcription, less rRNA and ribosomal proteins. (D) Upon disruption of rRNA synthesis in these cells, the levels of free ribosomal proteins remain low with little binding of Rpl5 and Rp111 to Mdm2. Thus, Mdm2 continues to bind to and ubiquitinate p53 targeting it for degradation, which helps to keep p53 protein levels low in support of cell survival. 
Table S1. (separate file)

Proteins identified by multidimensional protein identification technology with

TCOF1/TREACLE as the bait or the 293 Control.

Table S2. (separate file)

List of primers used for genotyping and RT-qPCR. 


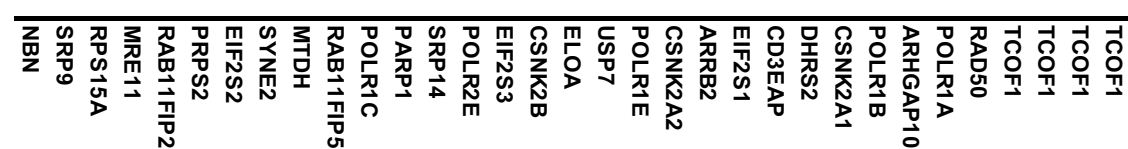

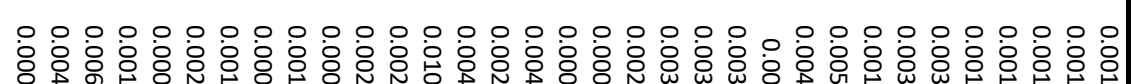

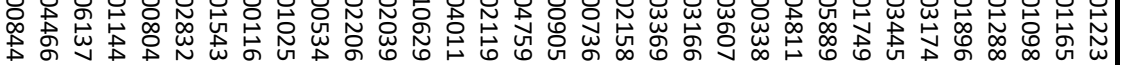

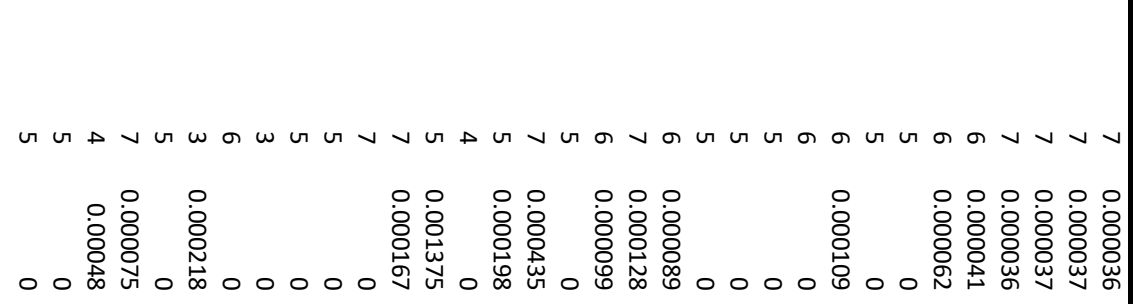

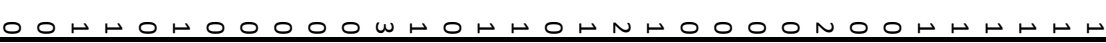

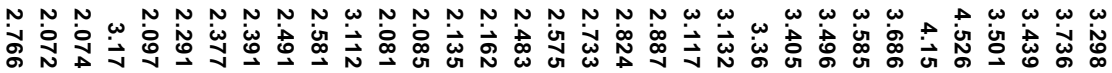

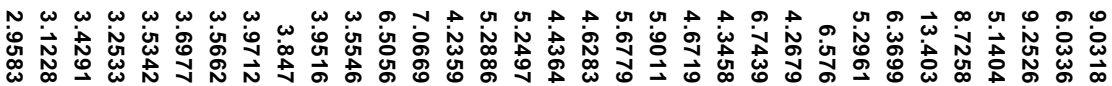

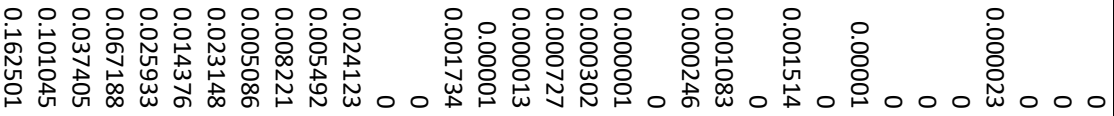

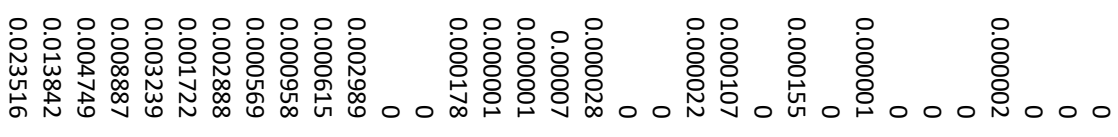

N

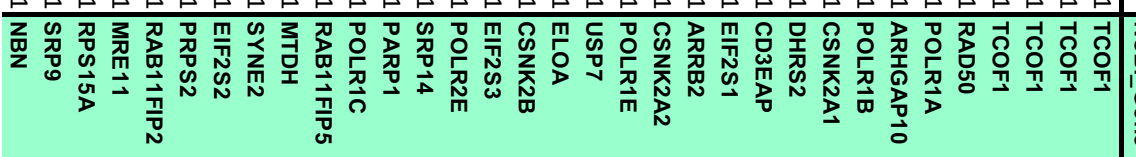

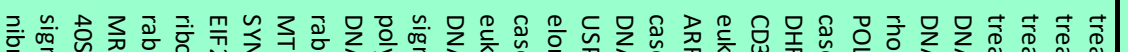

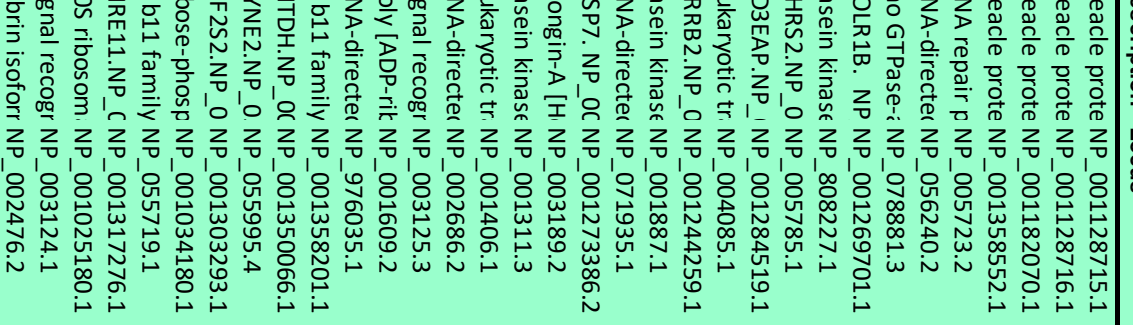


bioRxiv preprint doi: https://doi.org/10.1101/2021.09.22.461379; this version posted September 22, 2021. The copyright holder for this preprint

(which was not certified by peer review) is the author/funder, who has granted bioRxiv a license to display the preprint in perpetuity. It is made available under aCC-BY-NC-ND 4.0 International license.

Supplemental Table 2. List of primers used for genotyping and RT-qPCR.

Forward

\begin{tabular}{l}
\hline Polr1a-WT \\
Polr1a-PostFlp \\
Polr1a-floxed \\
Polr1a-Cre-excised \\
5'ETS \\
28S \\
Gapdh \\
B2m \\
canx \\
Polr1a-exon1 \\
p53 \\
Tcof1-exon \\
Polr1c-exon3 \\
p21
\end{tabular}

Reverse

GATGCAGTTGGCAATTTCAAGACC GATGCAGTTGGCAATTTCAAGACC GAGATGGCGCAACGCAATTAATG GATGCAGTTGGCAATTTCAAGACC CAGAATGCCCTTGGAAGA GGGTGGTAAACTCCATCTAA TGGCCAAGGTCATCCATGA CACTGACCGGCCTGTATGC CCAGACCCTGATGCAGAGAAG CCGAAGAGCTCAAGAAGTTA TCTCCGAAGACTGGATGA CGTGCACGTGAATCCCCT TATGATGATGCCTGGGAC GACAAGAGGCCCAGTACTTC
CGGTGTGCTTTCTGCTTCATGC CGGTGTGCTTTCTGCTTCATGC GACCCAAATGTGGAGCATAAGACACC GACCCAAATGTGGAGCATAAGACACC ACACAGGGAAACCAGAAG CCCTCTTGAACTCTCTCTTC CAGTCTTCTGGGTGGCAGTGA GGTGGCGTGAGTATACTTGAATTTG CCTCCCATTCTCCGTCCATA GACCCAAAGCCAAATCATAC CTGGAGGAAGTAGTTTCCATAA CCGCTCTGCTCCTTTACTTCC TCGGCACCTCAGCTAACA GCTTGGAGTGATAGAAATCTGTC 